\title{
Porous Polymer Tape Screening Program
}

Keywords:

Cables

Tape

Porosity

Testing

Polymer

Permeation

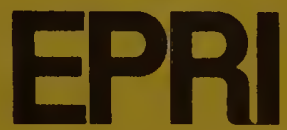

EPRI EL-1259

Project 7864

Final Report

December 1979 



\title{
Porous Polymer Tape Screening Program
}

\author{
EL-1259 \\ Research Project 7864 \\ Final Report, December 1979
}

\author{
Prepared by \\ NATIONAL BUREAU OF STANDARDS \\ Polymer Science and Standards Division \\ Washington, D.C. 20234 \\ Principal Investigator \\ A. J. Bur
}

Prepared for

Electric Power Research Institute

3412 Hillview Avenue

Palo Alto, California 94304

EPRI Project Manager

Bruce S. Bernstein

Electrical Systems Division 


\section{ORDERING INFORMATION}

Requests for copies of this report should be directed to Research Reports Center (RRC), Box 50490, Palo Alto, CA 94303, (415) 961-9043. There is no charge for reports requested by EPRI member utilities and affiliates, contributing nonmembers, U.S. utility associations, U.S. government agencies (federal, state, and local), media, and foreign organizations with which EPRI has an information exchange agreement. On request, RRC will send a catalog of EPRI reports

Copyright (C) 1979 Electric Power Research Institute, Inc

EPRI authorizes the reproduction and distribution of all or any portion of this report and the preparation of any derivative work based on this report. in each case on the condition that any such reproduction. distribution, and preparation shall acknowledge this report and EPRI as the source.

\section{NOTICE}

This report was prepared by the organization(s) named below as an account of work sponsored by the Electric Power Research Institute, Inc. (EPRI) Neither EPRI, members of EPRI, the organization(s) named below, nor any person acting on their behalf: (a) makes any warranty or representation, express or implied, with respect to the accuracy. completeness, or usefulness of the information contained in this report, or that the use of any information, apparatus, method, or process disclosed in this report may not infringe privately owned rights: or (b) assumes any liabilities with respect to the use of, or for damages resulting from the use of, any information, apparatus, method, or process disclosed in this report.

Prepared by

National Bureau of Standards

Washington, D.C. 


\section{ABSTRACT}

A screening program has been developed for porous polymer tapes which are considered to be candidates for a tape-oil insulation system in a high-voltage transmission cable. The program consists of 21 tests for measuring mechanical, electrical and physical properties. Descriptions of most of these tests have been published in ASTM test schedules or in other literature sources. Two of the tests had to be developed in our laboratories. They are the degree-of-void-filling test and the solubility test.

For the degree-of-void-filling test, a buoyancy measurement is utilized to calculate the void volume which is not filled by the permeating oil. Two buoyancy measurements are made: first, the specimen is immersed in a calibration fluid which is assumed to permeate all voids in the specimen. A true specimen density is calculated and then compared to an apparent density which is obtained from the specimen immersed in oil. The difference in the two densities is proportional to the reciprocal of the unfilled void volume.

Four materials and two oils have been used for these experiments. The materials are a polypropylene synthetic paper (PPSP), a porous polypropylene (PP), a polyethylene synthetic paper (PE) and a paper-polypropylene-paper laminate (PPP). The oils are an alkyl benzene $0 i 1$ and a polybutene oil. The results show a range of void filling from very little for PPSP to complete filling for PP. 


\section{EPRI PERSPECTIVE}

\section{PROJECT DESCRIPTION}

The electric power cable industry has always lacked a coordinated way to evaluate porous tape materials for potential use as paper substitutes in laminar dielectrics. Although a number of screening tests have been generally employed by suppliers, there was no consensus on the testing scope, or on the priority to be assigned to the value of existing tests. Furthermore, it has not been clear whether existing tape screening tests are fully adequate. Consequently, cable manufacturers have found it necessary to test model cables in order to develop meaningful information. This approach is unnecessarily costly and not fully revealing. The purpose of this project was to formulate a screening program and to develop any experimental methods required to evaluate porous tapes, as part of that screening program.

\section{PROJECT OBJECTIVES}

The specific objectives of this project were to (a) establish criteria for properties that synthetic porous tapes must meet, (b) describe test methods for measuring these properties, (c) develop new test methods that may be required to support the test program.

\section{PROJECT RESULTS}

A three-phase screening program for porous polymer tapes was developed. The phases comprise a series of 21 tests (12, 6 and 3 per phase, respectively), to be employed sequentially. Phase $I$ is designed to rapidly eliminate unsatisfactory materials; Phase II focuses on dielectric and mechanical properties of the tape in oil, and Phase III provides for an aging interval in oil under combined dielectric, thermal and mechanical stress. Phase I data can be utilized to develop Pirelli equation data on dry tapes, and Phase II data can be used to develop similar data for oil-immersed tapes. As part of the screening program, the contractor, the National Bureau of Standards, developed a method to quantitatively measure the void-filling capability of porous polymer tapes. The method consists of measuring the buoyant force of a porous tape immersed in a 
dielectric oil relative to immersion in a calibration fluid. The equipment required for this test is a Cahn electrobalance. The National Bureau of Standards also developed a test for accurately determining the solubility of porous tapes in oils, and developed a set of recommended guidelines on acceptable levels of performance. The program that has been developed and the acceptance guidelines are recomended as a guide, and may be further refined as additional test data are developed by the Industry.

As a result of this work, the Industry now has available a method for reliably measuring the porosity of tapes for dielectric applications, and a programed approach for screening porous tapes prior to preparing model cables.

Bruce Bernstein, Project Manager Electrical Systems Division 


\section{ACKNOWLEDGMENTS}

The principal investigator wishes to acknowledge the contributions of Or. Robert W. Penn and Mr. William P. Harris. Or. Penn made measurements of compression modulus on stacks of paper tapes and helped to develop test Nos. 12 and 16 of this program. Mr. Harris prepared many of the test descriptions in Section 4 and carried out most of the editorial work for this report. Also, special acknowledgments are due to Drs. Freddy A. Khoury and Martin G. Broadhurst for many helpful discussions with the author during the course of this work. The author acknowledges the consultations and assistance of Mr. Edward D. Eich during the early stages of this program. 


\section{CONTENTS}

Section

Page

1 INTRODUCTION

$1-1$

2 SELECTION OF PHYSICAL PROPERTIES 2-1

Assumptions on Which Selections of Tests are Based 2-1

Consideration of the Assumptions 2-2

Tests Eliminated from the Program 2-2

Choice of Tests to be Included in the Program 2-4

3 ACCEPTANCE CRITERIA 3-1

The Pirelli Equations 3-1

Application of the Pirelli Equations 3-2

4 THE TEST PROGRAM 4-1

Using the Test Program 4-2

Notes to Table 4-1 4-3

5 VOID-FILLING TEST 5-1

Calculation of Unfilled Void Volume 5-1

Case 1: No Swelling, No Solubility 5-1

Case 2: Swelling 0ccurs, but no Solubility 5-2

Testing the Hypothesis $5-3$

Result $5-4$

Experimental Apparatus $\quad 5-5$

Calibration $5-6$

Measurement of Liquid Densities $\quad 5-7$

Specimen Preparation $\quad 5-8$

Procedure 5-10

Experimental Results $\quad 5-15$

6 SOLUBILITY 6-1

7 CONCLUSIONS 7-1

8 REFERENCES 8-1 


\section{ILLIUSTRATIONS}

Figure

Page

4-1 Apparatus for Tests 5,17 and 18

4-5

4-2 Suggested Grip Modification for Tests 12 and 16

4-11

4-3 Suggested Testing Machine for Tests 12 and 16

4-13

4-4 Stacked Specimen in Testing Machine

4-14

4-5 Suggested $0 i 1$ and Thermal Chamber for Tests 15 and 19

4-15

4-6 Stress Unit for Tests 19 and 20

4-20

4-7 Grips for Stressing Material for Tests 19 and 20

4-21

5-1 Schematic Diagram of Cahn RG Automatic Electrobalance

5-2 Block Diagram of Buoyant-Force-Measuring System

$5-7$

5-3 Specimens for Void-Filling Test

5-10

5-4 Specimen of PPP Suspended in 0 i1

5-5 Dr. A. J. Bur Operating the Void-Filling-Test Apparatus

5-6 Buoyancy of PPSP in Heptane vs. Time

5-7 Buoyancy of PPSP in Polybutene vs. Time

5-8 Buoyancy of PE in AIkyT Benzene Dil vs. Time

5-9 Buoyancy of PE in Polybutene $0 i 1$ vs. Time

5-10 Buoyancy of PP in Alkyl Benzene 0il vs. Time

5-11 Buoyancy of PP in Polybutene 0il vs. Time

5-20

5-12 Buoyancy of PPP in ATkyl Benzene $0 i 1$ vs. Time 


\section{TABLES}

Table

Page

3-1 Physical Properties and Criteria - Phase 1 Screening

3-3

3-2 Physical Properties and Criteria - Phase 2 Screening

$3-4$

3-3 Physical Properties and Criteria - Phase 3 Screening

3-5

4-1 The 21-Test, 3-Phase Screening Program

5-1 Effect of Swelling on Density

5-2 Densities of Liquids $4-25,4-26$

$5-4$

5-8

5-3 Properties of Dielectric 0ils

5-9

5-4 Void Filling at Room Temperature, Alkyl Benzene

5-16

5-5 Void Filling at Room Temperature, Polybutene

$5-16$

6-1 Solubility of Tapes at Room Temperature

6-2 
SUMMARY

PURPOSE AND SCOPE

For many years oil-permeated paper tape has been used for the insulation of highvoltage underground transmission cables. In the future, increased electrical energy consumption will create new demands on the performance of insulating materials. Synthetic polymer tapes are promising candidates for use as high-performance alternative materials. But to be a usable cable insulation, a substitute must possess certain attributes important to the manufacture, installation, and life in service of a cable. These needed properties include electrical, chemical and mechanical factors.

The purpose of this study was to assemble a comprehensive screening procedure - a series of tests to be used to eliminate unusable materials from further extensive testing, without eliminating potentially useful materials.

\section{METHOD OR PROCESS}

There are two important elements of this study:

Selection of the properties to be evaluated in the screening

Assembly of appropriate tests for the selected properties

The selection of properties to be evaluated was based on the following assumptions:

1. The most demanding physical properties for this application will receive the greatest emphasis. These are porosity properties and mechanical and dielectric properties.

2. The screening tests should simulate the conditions found in the operating cable.

3. As a substitute for paper, the polymer should perform as well as paper for the same operating conditions.

4. Properties for which acceptance criteria could not be established are excluded from the measurement program.

5. Properties judged of secondary importance, such as thermal conductivity, should not be measured in the screening program.

6. With the exception of the Pirelli criteria, parameters related to cable construction are not considered in the screening program or tests. 
7. The overall physical properties of a candidate tape material must be considered to determine its suitability as cable insulation.

8. Testing of model cables are not included in this program.

9. Economic factors are not considered.

Consideration of the assumptions led to the rejection of tests for some properties, and the final selection of 21 tests, to be applied in three phases.

Of the 21 tests selected, all but two were available as published tests or descriptions of work done. It remained to develop tests for the degree of void filling by an oil impregnant, and for solubility in the oils commonly used as impregnants.

The experimental work developing the degree-of-void-filling test was a considerable part of this project.

For each test chosen, an appropriate level of performance had to be established, on which decisions of acceptance or rejection for further testing could be based. Setting these levels was necessarily somewhat arbitrary, but were based on the general premise that performance should equal or better that of the oil-impregnated cellulosic paper in current use. This follows from the fact that the ultimate goal, of which this study is one component, is the development of a substitute for oil-impregnated paper that will out perform the paper.

The performance criteria are set forth in Tables 3-1 to 3-3.

\section{THE RESULT}

The screening program is presented in matrix form (Table 4-1) in the report. The rows are the 21 tests selected; the columns are the eight elements that comprise a test.

\section{The 21 Tests}

Phase 1 Tests.

1. Dielectric Constant vs. Temp. to $120^{\circ} \mathrm{C}$

2. Loss Tangent vs. temp. to $120^{\circ} \mathrm{C}$

3. AC Breakdown, $23^{\circ} \mathrm{C}$ and $120^{\circ} \mathrm{C}$

4. Stress-Strain at $23^{\circ} \mathrm{C}$

5. Coefficient of static friction - dry.

6. Solubility at 23,90 , and $120^{\circ} \mathrm{C}$

7. Softening Temp.

8. Melting Temp.

9. Degree of Void Filling

10. Dimensional Uniformity

11. Shear Modulus

12. Compression modulus on stack, dry, $23^{\circ} \mathrm{C}$. 
Phase 2 Tests.

13. Impulse breakdown in $0 i 1$ at 23 and $120^{\circ} \mathrm{C}$

14. AC breakdown on stack of tapes in 011,23 and $120^{\circ} \mathrm{C}$

15. Stress-Strain in $0 i 1$ at $23,90,120^{\circ} \mathrm{C}$

16. Compression modulus on stack, in $0 i 123^{\circ} \mathrm{C}$

17. Swelling force, stack in $011,23^{\circ} \mathrm{C}$

18. Wet coefficient of friction

Phase 3 Tests.

19. Stress-strain $23^{\circ} \mathrm{C}$, sample aged at $120^{\circ} \mathrm{C}$, in vacuum-treated oi , under mechanical and electrical stress.

20. Impulse and $A C$ breakdown $23^{\circ} \mathrm{C}$, specimen aged at $120^{\circ} \mathrm{C}$, in vacuuritreated oil, under mechanical and dielectrical stress.

21. Creep and recovery $23^{\circ} \mathrm{C}, 90^{\circ} \mathrm{C}$.

The Eight Elements of Each Test

1. Specimen Selection, Number and Dimensions

2. Conditioning

3. Apparatus

4. Procedure

5. Precautions

6. Calculation or Interpretation of Results

7. Report

8. Precision and Accuracy

Notes to Table 4-1

The limited space available in the blocks of Table 4-1 were insufficient to hold a 11 the information needed in many cases. For these, the block carries a reference to a corresponding note. There are 22 pages of notes.

\section{CONCLUSIONS}

It is suggested that this screening program will be used in the following manner:

- A suitable quantity of each candidate material will be made available to the testing laboratory employed to perform the tests.

- Phase 2 tests will be made only on those candidate materials that successfully meet all Phase 1 criteria.

- Phase 3 tests will be made only on those candidates that meet Phase 2 criteria.

- Within each phase, agreements will be reached as to the order in which the tests are to be performed.

- Agreements will be made concerning when to discontinue the testing due to clear failure of a material to meet the criteria for the tests. 
Section 1

INTRODUCTION

For many years paper tape permeated with dielectric oil has been used for the insulation of high voltage underground transmission cables. Significant changes and improvements in the paper-oil system have been made over the years so that its reliability and durability in the present operating environment is well recognized. For the future, however, increasing electrical energy consumption will create new demands on the performance of insulation materials. It is projected that transmission voltages of $1000 \mathrm{kV}$ or higher will be needed. The reliable performance of paper-oil cable at such high voltages is in question because of high-voltage-induced ionization in the cellulose and because forced cooling would be necessary. New improved insulation materials to meet these new demands are being sought, and synthetic polymer tapes are promising candidates.

A considerable amount of development work on polymer tapes has been carried out over the past fifteen years. Initially solid polymer films were studied for this application, but recently, in order to facilitate the flow of oil between tape layers, porous tapes, synthetic papers and paper-polymer film laminates have been developed $(1-11)$. In these programs various approaches were taken. In all cases except ( $\underline{7})$, the early development included experiments with model cables. The various screening programs were not well defined, nor did they uniformly include the same physical property criteria and tests. Properties which were of common concern are swelling, solubility, modulus, tensile strength, dielectric properties, and dielectric strength. Other properties which were focused upon in some programs are: coefficient of friction, dimensional uniformity $(\underline{3})$, softening temperature ( $\underline{3})$, stress-strain characteristics (1), creep and recovery (1), wetting (10), stiffness (2)), and partial discharge (corona) inception level (2).

Most notable is the work done at Illinois Institute of Technology Research Institute (IITRI), to develop polymer tapes from 1962 to 1967 (1). In the IITRI program, the tests which were employed reflected the demands of the environment in the cable, i.e. tests were carried out over a wide temperature range in $0 i 1$. Mechanical and dielectric tests were emphasized and other properties were given 
secondary emphasis. For example, solubility and swelling were not measured directly but their effect on mechanical properities was observed. The materials that showed the most promise as polymer tapes were solid films of polycarbonate, polyphenylene oxide and polysulfone.

Phelps Dodge Cable and Wire Co., and General Cable Corporation also have had extensive programs to find a polymer substitute for paper tape $(\underline{2,3})$. In both cases, their screening programs el iminated all synthetic polymer tapes in favor of PPP, a paper-polypropylene laminate. Some of the polymer tapes were el ininated by economic factors, which are not be be considered here. The screening programs were not definitive. Among the properties which were mentioned or described were solubility, swelling and dimensional stability. Swelling larger than $2 \%$ was considered to be excessive because oil flow in a model cable was significantly hindered $(\underline{2,6})$.

The development of two synthetic paper tapes, one of polyethylene ( $\underline{5}$ ) and the other of polypropylene ( 7 ), note special attention. The polyethylene tape is made from a highly crystalline fiber and was produced by the Furukawa Electric Co., Japan. The polypropylene tape was made by llatsushita Industrial Equipment Co., Japan. Both of these materials were made specifically for use as cable insulation. Samples of these materials were obtained by our laboratory and used in our experimental program.

Recent work has been on porous polymer tapes because it is recognized that tape porosity provides adequate oil flow in the wrapped cable configurations $(\underline{5}, \underline{7}, \underline{12})$. In this program one of our objectives is to quantitatively measure the degree of void filling by a dielectric oil and to measure the effect of void filling on other properties of an oil-immersed tape. Specifically, we have developed a degree of void filling test by which the amount of void volume unfilled by $0 i 1$ is measured.

Failure to use a screening program to quantitatively evaluate mechanical and electrical properties as well as porosity generated insoluble problems during one study (12). The objective of this project has been to develop a test prograri which can be used to examine porous polymer tapes and to assess their potential use in a porous polymer tape-0il insulation system. The screening program which we have developed is designed specifically for porous polymer tapes but it can also be used for solid polymer films. 
The actual selection of materials is beyond the scope of this study; selection is to result from the application of this series of tests.

In the course of putting together the test program it has been necessary to develop two tests which were not adequately described in the existing literature. These are the degree-of-void-filling test and the solubility test. To develop these tests, laboratory experiments were carried out on several porous polymer films immersed in a dielectric 0i1. A buoyant force measurement, described in Section 5 , was used to calculate the volume unfilled by the dielectric oil. 


\section{Section 2}

\section{SELECTION OF PHYSICAL PROPERTIES}

The tests and physical properties which we included in this progran are those which we determined to be essential for assessing the performance of a porous polymer tape. These tests will obviously include dielectric and mechanical measurements. Many other physical measurements have been used to test polymer and paper tapes and it is not so obvious which of these should be included. The selection process which we used involved making a list of reasonable assumptions and setting intermediate goals for the screening program.

\section{ASSUMPTIONS ON WHICH SELECTIONS OF TESTS ARE BASED}

The following assumptions are made:

1. The most demanding physical properties for this application will receive the greatest emphasis. These are porosity properties and mechanical and dielectric properties.

2. The screening tests should simulate the environmental conditions found in the operating cable.

3. As a substitute for paper, the polymer should perform as well as paper for the same operating conditions.

4. Properties for which acceptance criteria could not be established are excluded from the measurement program.

5. Properties judged of secondary importance, such as thermal conductivity, should not be measured in the screening program.

6. With the exception of the Pirelli criteria, parameters related to cable construction are not considered in the screening program or tests.

7. The overall physical properties of a candidate tape material must be considered to determine its suitability as cable insulation.

8. Testing of model cables are not included in the program.

9. Economic factors are not considered. 


\section{CONSIDERATION OF ASSUMPTIONS}

Consideration of assumptions 4, 5, and 6 led to the elimination of tests for the following physical properties:

- Air permeability

- Wetting angle

- 0 il flow

- Thermal conductivity

- Stiffness

- Tearing strength

- Folding endurance

- Partial discharge (corona)

- Swelling

While some of these properties are of importance to the cable designer, they are, in our judgement, of secondary importance to the screening program.

\section{TESTS EL IMINATED FROM THE PROGRAM}

\section{Air Permeability}

This test was eliminated because no acceptance criterion could be established. In the case of paper there is a relationship between this property and cable performance based on many years of experience. Without such experience with porous polymer tapes, it is not possible to assign a value of air permeability which indicates acceptance of a tape as cable insulation. Without the criterion of an acceptable value, there is no purpose in performing the test.

\section{Wetting Angle}

This is a physical property which we consider to be of secondary importance and therefore it is not included in the program. Certainly a zero wetting angle for an oil on a polymer tape will facilitate void filling and oil flow in the cable configuration. But, in this program we make a more direct measure of oil permeation into the porous tape using the degree-of-void-filling test. Thus, a wetting angle measurement becomes unnecessary.

\section{0il Flow Through the Porous Polymer Tape}

This is not a part of the screening program for the following reasons:

1. There is no information or data available by which oil flow through a single porous tape can be related to oil flow in the cable. 
2. Swelling of a single free-standing porous tape is different from swelling of the same tape in an enclosed cable, so that the effect of pore size is different for each environment. Also, the swellingpore size phenomenon would differ for different polymer materials.

3. While oil flow has been of concern $(\underline{2}, \underline{6})$, there are no data avai1able regarding the relationship between oil flow and performance of porous-polymer-tape cables.

\section{Thermal Conductivity}

The $I^{2} R$ heat losses in the center conductor must be conducted thru the tape-0i1 insulation to the ambient surroundings. It is the composite of tape and oil which determines the thermal conductivity and it is the thickness of the insulation which determines the heat flux for a given thermal conductivity. Diffusion as well as convection of $0 i 1$ are the mechanisms by which heat is conducted thru the tape-oil system. The thermal conductivity of the tape itself is not the single dominant factor. In our judgement thermal conductivity is of secondary importance.

\section{Stiffness, Tearing Strength, and Folding Endurance}

These are tests which have been developed over the years by paper-tape cable manufacturers. Their chief purpose is as a quality check on incoming paper material. Long experience with paper has established a correlation between these tests and cable performance. Folding endurance, for example, is used to detect the degradation of cellulose in paper due to pyrolysis (8). For polymer tapes, correlation between folding tests and cable performance has not been established.

\section{Partial Discharge Inception Level}

After a review of the use of partial discharge (corona) inception level measurements, we have recognized its limitations for detecting voids. In the cable industry partial discharge testing is done on finished cables to detect large flaws which may have been introduced during manufacture. The state-of-the-art partial discharge measurement is not developed enough so that it can be used as a routine test to detec $\iota$ microvoids in insulating tapes.

\section{Swelling}

Swelling of a single tape in the free state has been eliminated from the test schedule because an acceptance criterion cannot be established. The problem which a swollen tape causes is not going to be ignored, however. In the cable configuration a swollen tape hinders oil flow and also causes an increase in radial stress. 
If swelling is excessive then it is possible that radial stress can reach a critical level and contribute to fracture $(\underline{4}, \underline{6})$. When the tape is physically confined in space, the swelling is confined to filling spaces between layers and butt gaps and there is a resultant increase in radial stress (6). In the Pirelli analysis (13), the bending force is proportional to the radial stress. Thus, if the radial stress becomes too high, then the critical buckling stress for the tape can be exceeded. On the positive side, a sample which swells will allow oil to penetrate into microvoids which might be less accessible with a non-swelling material. Thus, some swelling can be accommodated, but it is desirable that it be held to a minimum. A test to measure the increase in radial pressure due to swelling has been described in the literature $(\underline{6}, \underline{14})$.

\section{CHOICE OF TESTS TO BE INCLUDED IN THE PROGRAM}

\section{The Goals}

The intermediate goals which we established for the screening program indicated the physical properties and tests which were finally included. These goals are:

1. A test will be devised to measure oil penetration or the degree of void filling in a porous tape.

2. Consideration will be given to the specific behavioral characteristics of polymer materials, e.g. creep and receovery and softening temperature.

3. Dielectric and mechanical measurements are the essential core of the test program.

4. Mechanical measurements on the dry tape must yield enough information to calculate the cable bending stress and critical bending stress using the Pirelli equations.

5. Likewise, mechanical measurements on the wet tape must yield enough information to use the Pirelli equations relating to the bending of an oil-permeated cable.

6. Mechanical measurements at elevated temperatures are needed for assessing the environmental integrity of tape material.

\section{The Choices}

The tests, physical properties and acceptance criteria of the screening programs are shown in Tables 3-1, 3-2 and 3-3. The list contains the essential dielectricand mechanical-property tests, as well as tests which we judge to be necessary for porous polymer materials, i.e. the softening temperature, the melting temperature, the degree of void filling, solubility and the creep and recovery tests. 


\section{The Three Phases}

Note that the screening program is divided into three phases. Each phase has a specific goal:

- Phase 1 is designed to eliminate the most undesirable materials with simple and inexpensive tests. Also, in Phase 1, all of the necessary information needed for utilizing the Pirelli equations for the dry cable is obtained.

- In Phase 2 dielectric and mechanical properties of tapes in oil at elevated temperature are measured. The data can be used to analyze wet cable characteristics using the Pirelli equations.

- In Phase 3, longer term effects of temperature, $0 i 1$, and dielectric and mechanical stresses will be obtained. Here, specimens are kept in $0 i 1$ under stress for periods up to several months, after which their mechanical and dielectric properties are measured at room temperature. The aging time chosen is arbitrary, but fel $t$ to be reasonable for a screening program. 



\section{Section 3}

\section{ACCEPTANCE CRITERIA}

The criteria of Tables 3-1, 3-2 and 3-3 were determiner by revieuing other development programs, by applying the Pirelli equations, by using assumption 3 (See page 2-1), and by applying absolute contitions such as in test.s 9, 19, and 20. These absolute conditions are conservative criteria, and could possibly be relaxed when more information is available regarding cable performance.

It should be understood that some flexibility with regard to the application of these criteria may be appropriate. A material for which a fely property values are borderline can sometimes be accomodated by engineering and cable design parameters. Also, a trade-off between a desirable material property and a marginal property can be considered in making the judgment about a polymer tape.

\section{THE PIRELLI EQUATIONS}

The mechanics of bending for a wrapper cable have heen described by the pirelli theory (13). This theory has been experimentally verified and used in practice for papertape cable manufacturing. The major material difference between paper and polymer tapes is that a stress relaxation will occur in a polymer tape which does not occur in paper tapes. In spite of this difference, experience has shown that the Pirelli equations yield an adequate description for the mechanics of bending a polymer tape cable. These equations are the basis for the acceptance criteria of the mechanical properties tests.

According to the Pirelli theory, the force on a tape from bending a cable is

$$
N_{\text {bend }}=\frac{2}{3} \mu w \phi \text {, }
$$

where $\phi$, the radial pressure, is given by

$$
\phi=\frac{T}{s w} \cos ^{2} \alpha\left[\frac{E_{\ell}}{E_{c}}-1\right]^{1 / 2}
$$


$\mu \quad$ is the coefficient of friction, tape-to-tape.

w is the width of the tape.

T is the taping tension.

$s \quad$ is the tape thickness.

$\alpha \quad$ is the taping angle.

$E_{\ell}$ is the tensile modulus in the machine or long direction of the tape.

$E_{c}$ is the compressive modulus of a stack of tapes in a direction perpendicular to the surface.

We note that $N_{\text {bend }}$ has the dimensions of force per unit length. The force is directed perpendicular to the edge of a thin tape. If this force becomes too large it will cause the tape to buckle. The critical force per unit length for buckling is given by

$$
N_{\text {crit }}=\frac{S}{3 R}\left(4 \quad G^{2} E_{\ell} E_{t}\right)^{\frac{1}{4}}
$$

$R$ is the cable radius for the tape being considered.

$G$ is the shear modulus which results from an angular displacement whose direction is perpendicular to the tape.

$E_{t}$ is the tensile modulus in the cross machine direction i.e. perpendicular to the long direction of the tape and perpendicular to $E_{c}$.

\section{APPLICATION OF THE PIPELLI EQUATIONS}

A bending force is applied to a tape when a cable is wound on an uptake reel during manufacture or when it is unwound from the reel during installation. Given the material moduli $E_{\ell}, E_{C}, E_{t}$ and $G$, and the coefficient of friction, $\mu$, the other parameters of Eqs. 3-1, 3-2 and 3-3 are adjusted so that $N_{\text {bend }}<N_{c r i t}$ for all radii of the cable. Or, from another point of view, the moduli and coefficient of friction must have values such that the other parameters of the equations can be adjusted within practical limits. 
Table 3-1

\section{PHYSICAL PROPERTIES WI CRITERIA - PHF.SE 1 SSPEENIYS}

\begin{tabular}{|c|c|c|c|c|}
\hline Phy & ysical Property & $\begin{array}{l}\text { Fange of Acceptable } \\
\text { yaluesa }\end{array}$ & $\begin{array}{l}\text { Justification of nange } \\
\text { of Acceotable "zlues }\end{array}$ & $\begin{array}{l}\text { ournose--l'hat } \\
\text { h'e Can Learn }\end{array}$ \\
\hline 1) & $\begin{array}{l}\text { Dielectric Constant } \\
\text { ys. temp. to } 120^{\circ} \mathrm{C}\end{array}$ & Less than 3.5 & Note $b$ & $\begin{array}{l}\text { Electrical } \\
\text { Perfomance }\end{array}$ \\
\hline 2) & $\begin{array}{l}\text { Loss Tangent } \\
\text { vs. temp. to } 120^{\circ} \mathrm{C}\end{array}$ & Less than $0.2 \%$ & Note $b$ & $\begin{array}{l}\text { Electrical } \\
\text { Performance }\end{array}$ \\
\hline 3) & $\begin{array}{l}\text { AC Breakdown, } \\
23^{\circ} \mathrm{C} \text { and } 120^{\circ} \mathrm{C}\end{array}$ & $\begin{array}{l}\text { Greater than } \\
75 \mathrm{kV} / \mathrm{mm}\end{array}$ & Note $b$ & $\begin{array}{l}\text { Electrical } \\
\text { Performance }\end{array}$ \\
\hline 4) & $\begin{array}{l}\text { Stress-Strain at } \\
23^{\circ} \mathrm{C}\end{array}$ & Note $\mathrm{c}$ & Note $c$ & $\begin{array}{l}\text { Mechanical } \\
\text { Performance }\end{array}$ \\
\hline 5) & $\begin{array}{l}\text { Coefficient of } \\
\text { static friction } \\
\text { - dry. }\end{array}$ & Note $c$ & Note $c$ & $\begin{array}{l}\text { Taping chavacter- } \\
\text { istics, cable } \\
\text { behavior. }\end{array}$ \\
\hline 6) & $\begin{array}{l}\text { Solubility at } \\
23,90,1200 \mathrm{C} .\end{array}$ & $\begin{array}{l}\text { Less than } 1 \% \\
\text { (See inte d) }\end{array}$ & References $(\underline{2,3,5})$ & Film integrity \\
\hline 7) & Softening Temp. & Greater than $130^{\circ} \mathrm{C}$ & Note e & Film integrity \\
\hline 8) & Melting Temp. & Greater than $130^{\circ} \mathrm{C}$ & Note e & Film integrity \\
\hline 9) & $\begin{array}{l}\text { Degree of Void } \\
\text { Filling }\end{array}$ & Note $f$ & see text & $\begin{array}{l}\text { Elimination of } \\
\text { voids }\end{array}$ \\
\hline 10) & $\begin{array}{l}\text { Dimensional } \\
\text { Iniformity }\end{array}$ & $\pm 5 \%$ & Reference (3) & $\begin{array}{l}\text { ouality of manu- } \\
\text { factured ta?e }\end{array}$ \\
\hline 11) & $\begin{array}{l}\text { Shear Modulus } \\
23^{\circ} \mathrm{C}\end{array}$ & Note c & Note c & Cable behavior \\
\hline 12) & $\begin{array}{l}\text { Compression modulus } \\
\text { on stack, dry, } 23^{\circ} \mathrm{C}\end{array}$ & Note $c$ & Note $c$ & $\begin{array}{l}\text { Cable behavior } \\
\text { guide. }\end{array}$ \\
\hline
\end{tabular}

Notes follow Table 3-3 
Table 3-2

PHYSICAL PROPERTIES AND CRITERIA - OHASE 2 SCREENING

\begin{tabular}{|c|c|c|c|c|}
\hline \multicolumn{2}{|c|}{ Physical Property } & $\begin{array}{l}\text { Range of } \\
\text { Acceptable values }\end{array}$ & $\begin{array}{l}\text { Justification of Range } \\
\text { of Accentable Values }\end{array}$ & $\begin{array}{l}\text { Purpose-l/hat } \\
\text { l'e Can Learn }\end{array}$ \\
\hline 13) & $\begin{array}{l}\text { Impulse breakdown } \\
\text { in } 0 i 1 \text { at } 23 \text { and } \\
120^{\circ} \mathrm{C} \text {. }\end{array}$ & $\begin{array}{l}\text { Greater than } \\
150 \mathrm{kV} / \mathrm{mm}\end{array}$ & Note $b$ & $\begin{array}{l}\text { 5ffect of tempera- } \\
\text { ture on breakdown }\end{array}$ \\
\hline 14) & $\begin{array}{l}\text { AC breakdown on } \\
\text { stack of tapes in } \\
\text { oi } 123 \text { and } 120^{\circ} \mathrm{C} \text {. }\end{array}$ & $\begin{array}{l}\text { Greater than } \\
50 \mathrm{kV} / \mathrm{mm}\end{array}$ & Note $b$ & $\begin{array}{l}\text { Series stackin? of } \\
\text { faults in porous } \\
\text { tapes. }\end{array}$ \\
\hline $15 !$ & $\begin{array}{l}\text { Stress-strain } \\
\text { in oil at } 23 \text {, } \\
90,120^{\circ} \mathrm{C} .\end{array}$ & Note $c$ & Note $c$ & $\begin{array}{l}\text { jil compatibilitv- } \\
\text { effect on mectianical } \\
\text { properties. }\end{array}$ \\
\hline 16) & $\begin{array}{l}\text { Compression modulus } \\
\text { on stack, in oil } \\
23^{\circ} \mathrm{C} \text {. }\end{array}$ & Note $c$ & Note $c$ & $\begin{array}{l}\text { Cable behavior guide, } \\
\text { effect of swelling. }\end{array}$ \\
\hline 17) & $\begin{array}{l}\text { Swelling force, stack } \\
\text { in oil, } 23^{\circ} \mathrm{C} \text {. }\end{array}$ & Note $c$ & Note $c$ & $\begin{array}{l}\text { Effect of swelling } \\
\text { or radial pressure. }\end{array}$ \\
\hline 18) & $\begin{array}{l}\text { Wet coefficient of } \\
\text { friction. }\end{array}$ & Note $c$ & Note $\mathrm{c}$ & $\begin{array}{l}\text { Cable behavior guice, } \\
\text { effect of swelling. }\end{array}$ \\
\hline
\end{tabular}

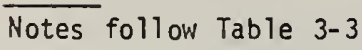


PHYSICAL PROPERTIES AND CRITE?IA - PHASE 3 SCREENING

Physical Property

\begin{tabular}{ll} 
Range of & Justification \\
Acceptable & of Range of \\
Valuesa & Acceptable Values \\
\hline
\end{tabular}

Purpose- What We can Learn

19) Stress-Strain $23^{\circ} \mathrm{C}$, specimen aged at $120^{\circ} \mathrm{C}$, in vacuum-

No significant treated oi 1 under mechanical and electrical stress.

20) Impulse and $A C$ breakdoisn, $23^{\circ} \mathrm{C}$ specimen aged at $120^{\circ} \mathrm{C}$, in vacuumtreated oil, under mechanical and dielectric stress.

21) Creep recovery $23,90^{\circ} \mathrm{C}$.

\author{
No significant \\ change from \\ Phase 1 and 2 \\ data, Tables \\ 3-1, 3-2.
} change from Phase 2 data,

Table 3-2

Note $\mathrm{g}$

Loss of mechanical properties.
Note $g$

Loss of dielectric properties.

${ }^{\text {a }}$ Borderline values of these properties may be accommodated by cable tesign parameters.

bThese values have been measured for paper. As a substitute for paper, the value for the polymer tape should equal or better the value cited.

${ }^{\mathrm{C}}$ The Pirelli equations for polymer tapes describe the mechanics of the tape in the cable configuration. The equations relate the hending stress and the critical buckling stress to the coefficient of static friction, the modulus of elasticity ( $M$ ) and CMD), compression modulus of a stack, taping angle, taping tension and tape dimensions. The physical quantities of an acceptable material, vhen substituted in the Pirelli equations, will yield a bending stress which does not cause buckling or fracture. For this screening program, the acceptahle values of modulus, and coefficient of static friction $c$ an be obtainer hy applying the pirelli equation. Elongation at fracture should be greater than $3 \%$.

design and engineering parameters could be utilizer to accommodate higher values of solubility.

${ }^{\mathrm{e}}$ The $130^{\circ} \mathrm{C}$ minimum softening or melting temperature was chosen in order to accommodate high crystalline polyethylene tapes for which the melting temperature is in the range $130-135^{\circ} \mathrm{C}$.

Void filling should be complete, i.e. no unfilled void volume. A material is deemed to meet the criteria for this test if either a) all voids are filled, b) it meets the criterion for Tests 3 and 20.

Any significant change would indicate that a degradation phenomenon is occurring. Subsequent investigation of the material would involve aging experiments beyond the scope of this screening program.

$h_{\text {Here }} \varepsilon_{1}$ is the elastic strain of the tape due to an applied stress and $\varepsilon_{3}$ is the unrecoverable strain after the stress is released. 


\section{Section 4}

THE TEST PROGRAM

The three phase test program is presented in matrix form in Table 4-1. The tests are numbered 1 through 21 , and are the row headings. The columns of the matrix are numbered 1 through 8 and are the elements considered to be necessary in a test description: Specimen Selection, Number and Dimensions; Conditioning; Apparatus; Procedure; Precautions; Calculation or Interpretation of Results; Report; Precision and Accuracy.

The broader subject of sampling plan design is not addressed in this study. It is assumed that the sample employed for this study is representative of the material. It is also assumed that the amount of material is enough to carry out the tests of this screening program.

The elements of the matrix are designated in the usual manner. For example, (13*2) refers to the conditioning of the specimen for the impulse breakdown in oil at 23 and $120^{\circ} \mathrm{C}$ test. Note that we are using the asterisk (*) to separate the row from the column numbers, to avoid confusion with page numbers.

Whenever possible, we have relied on the ASTM test descriptions. 0ther test schedules were consulted but the ASTM tests were superior in every category which we considered. Some tests were not available from ASTM or other test publications, in which case we relied on published descriptions of experiments. These non-ASTI experiments were not presented in the thorough, detailed ASTM format, so that the task remained for us to refine the protocol for these tests.

For precision of reference, the ASTM tests cited include a year designation. Those cited are the ones that appear in the ASTM Book of Standards for 1978, the latest available at the time of this study (15).

Those blocks of the matrix which are not sufficiently described by the notation therein, are set forth in more detail below in the notes to Table 4 , with the exception of the degree of void filling test and the solubility test which are described in Sections 5 and 6 of this report. 
For convenience of handling, the notes to Table 4-1 are placed ahead of the Table, beginning on page 4-3.

Table 4-1 appears on pages 4-25 and 4-26.

\section{USING THE TEST PROGRAM}

The grouping of the tests into the three phases is an essential element of the program. The tests of Phase 2 should not be executed until the material has successfully passed the acceptance criteria for all the tests in Phase 1. Likewise, the tests of Phase 3 are not carried out until the successful completion of Phase 2 tests. The reason for this is to avoid unnecessary and expensive testing on materials which are not acceptable.

To use Tables 3-1, 3-2 and 3-3 for the purpose of carrying out a test program some practical judgments are required. With each phase, a decision must be made concerning the sequence in which the tests are executed. The order in which they are listed here is somewhat arbitrary. It is neither the sequence of execution nor the order of importance. For example, in Phase 1, test 3 can not be carried out until the impregnation procedure is developed in test 9 . The impregnation procedure is also a prerequisite to all of the tests of Phases 2 and 3.

Application of the acceptance criteria of Tables 3-1 thru 3-3, requires judgments based on experience and knowledge of cable performance and construction. A material should be labelled unacceptable only after all efforts have been made to accommodate test failures. As mentioned above, this accommodation can be a trade-off between a good physical property and another which is below the acceptance criterion. Also, cable engineering design parameters can be used to accommodate borderline physical properties. 
NOTES TO TABLE 4-1

\section{Test 1. Dielectric Constant}

1*3 Apparatus. 1) Means of controlling and measuring temperature.

2) Capacitance and dissipation factor bridge, or other suitable circuit

3) Generator or other source of sine-wave excitation, operating at $60 \mathrm{~Hz}$.

4) Detector having sufficient sensitivity to provide resolution in dissipation factor of $2 \times 10^{-5}(0.00002)$ or 1 percent of the reading, whichever is higher.

5) Electrodes

Helpful information on apparatus appears in ASTM D 150-74 and in ASTM D202-77, Sec. 144.

$1 \star 4$ Procedure. Values of the dielectric constant (permittivity) and loss tangent (dissipation factor) are to be obtained for the following temperatures: $23,50,70$, 90 and $120^{\circ} \mathrm{C}$. This can be done by making measurements at these temperatures, or by interpolating from a curve derived from measurements made at other temperatures covering this range. The separation of actual measurement temperatures shall not exceed the intervals given above. No extrapolation is permitted.

Test 3. AC Breakdown at $23^{\circ} \mathrm{C}$ and $120^{\circ} \mathrm{C}$ in $0 \mathrm{il}$

$3 * 2$ Conditioning. Impregnation is required. The exact procedure for impregnation will be affected by the results of the test for degree of void filling, test 9 .

3*3 Apparatus. At first glance, it seems that using one-inch electrodes, instead of two-inch, would save a lot of material needed for tesing. Not so, for in any case, normal practice is to use a $15 \times 15 \mathrm{~cm}$. square specimen. The extra material is needed to prevent flashover.

Even when 1/4" electrodes are used, flashover problems dictate as large a specimen as can be spared.

$3 \star 5$ Precautions. Keep oil clean. Do not allow carbon particles to increase conductivity of oil. Replace or filter oil if carbon builds up from repeated heavy breakdowns. Note whether breakdowns are merely surface flashovers or punctures through the material. 
Breakdowns often cause asperities to develop on one or more of the electrodes. If this occurs, the asperities must be removed before further use. Polishing or lapping is the usual method for doing this. If the electrodes were properly made, reapplication of the techniques by which the electrodes were originally polished is desirable.

3*8 Precision and Accuracy. Precision of breakdown tests is generally low. Only in the case of single-operator tests performed on the same apparatus can the coefficient of variation be expected to be under $10 \%$. This refers to repeated tests of five specimens each, with all specimens coming from the same sample.

Many factors other than the intrinsic properties of the material affect the outcome of a breakdown test. These include:

--Thickness and uniformity of thickness of the specimen

--foriegn matter included in the material

--dirt on the surface of the specimen

--asperities on the electrodes

--transient surges (spikes) on the applied voltage waveform

--variations in pressure on the electrodes

--variations in the surrounding medium. 
Test 5. Coefficient of Static Friction, Dry. $23^{\circ} \mathrm{C}$.

$5 * 1$ Specimen Selection, Number and Dimensions. The test for the coefficient of static friction is described in Reference (14). Specimen size is approximately $5 \mathrm{~cm}$ square. Four specimens for each direction, MD and CMD, should be used.

$5 * 3$ Apparatus. Consists of two flat metal plates between which layers of the material are sandwiched. The sandwich is compressed by adding weight to the top plate, so the pressure on the stack is in the range $2 \times 10^{4} \mathrm{~N} / \mathrm{m}^{2}$ to $12 \times 10^{4} \mathrm{~N} / \mathrm{m}^{2}$. A film, which is sandwiched between two adjacent films, is attached by grips to a weight on a cord over a pulley. A sketch of this apparatus is shown in Figure 4-1.

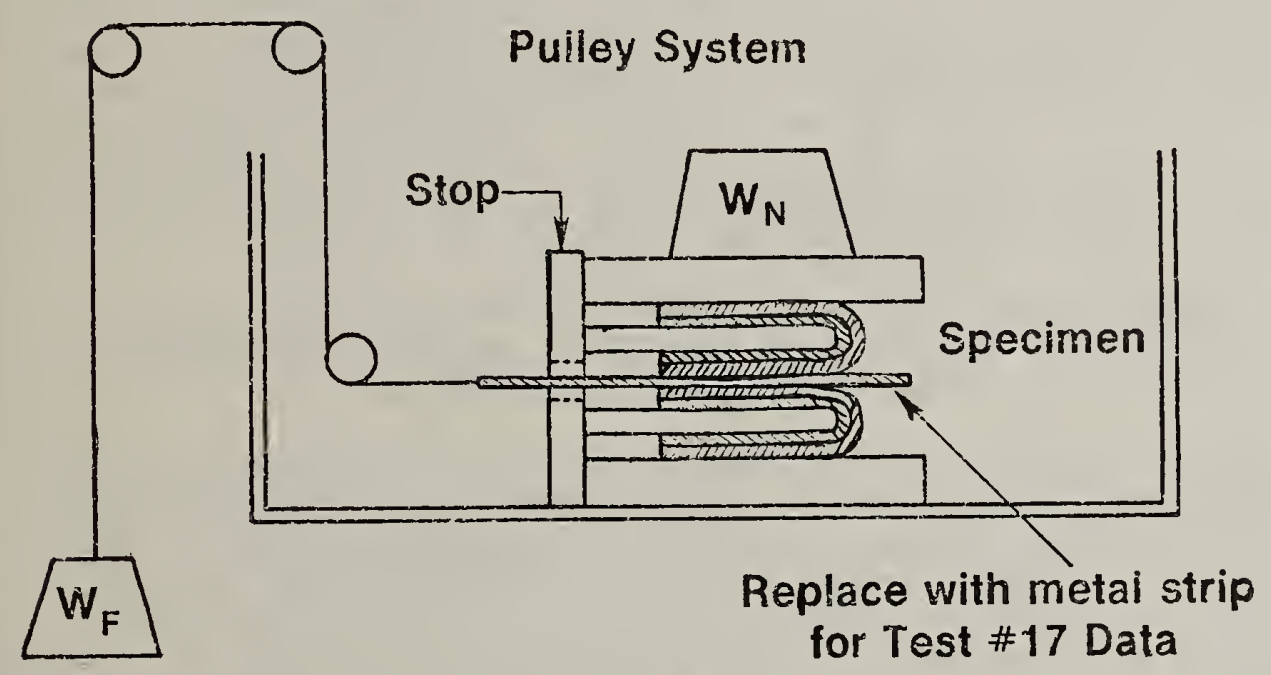

Figure 4-1. Apparatus for Tests $5,17,18$

$5 * 4$ Procedure. The measurement of the coefficient of friction is obtained by measuring the force which is necessary to just initiate movement of the film. The weight hanging on the cord over the pulley is increased by adding lead shot or other small increments of weight. A motion indicator such as a displacement transducer or microswitch may be used.

Test 7. Softening Temperature

$7 * 8$ Precision and Accuracy. Precision and accuracy of the softening temperature by the ASTM method has not been determined. 


\section{Test 8. Melting Temperature}

8 * 8 Precision and Accuracy. Precision of the melting temperature by the ASTM method is $\pm 2{ }^{\circ} \mathrm{C}$. The accuracy of this test has not been determined.

\section{Test 9. Degree of Void Filling}

\section{$9 * 4$ Procedure.}

1. The calibration fluid shall be chosen according to the following criteria: it must efficiently permeate the polymer under test; it must not dissolve the polymer at room temperature; and it must be a volatile liquid which mixes with the dielectric oil.

2. Before undertaking the buoyant force experiments, the solubility of the tape in the calibration fluid shall be measured. To do this, a specimen, weighing approximately $50 \mathrm{mg}$, shall be weighed to the nearest 0.01 $\mathrm{mg}$ using the electrobalance. Then immerse the specimen in approximately $50 \mathrm{~cm}^{3}$ of the fluid. Retain the vessel at room temperature and agitate twice daily over a period of several days. Upon removal from the fluid, the specimen is alternately weighed and vacuum dried until the specimen weight reaches a constant value. If the final weight of the specimen is within $\pm 0.01 \mathrm{mg}$ of the original weight, then, within the limits of accuracy of the measurement, the specimen is insoluble in the calibration fluid. This is the ideal case.

In the less-than-ideal case, some weight loss occurs. If the loss is less than $0.1 \%$, the fluid is considered to be marginally acceptable, and one or the other of two courses shall be followed:

a) short term solubility tests (for periods up to eight hours) can be carried out with new specimens, so that solubility vs. time data can be obtained, or b) the original specimen can be retested in order to determine if the weight loss is due to an initial cleaning which does not repeat upon further contact with the fluid. If initial cleaning was the reason for the weight loss, then a 11 subsequent specimens shal1 be given an initial cleaning before using them in the buoyant force experiment.

3. Four balance readings are necessary:

$A=$ Weight of wire loop and sinker in air,

$B=$ weight of wire loop and sinker plus specimen in air,

$C=$ weight of wire loop and sinker in fluid,

$D=$ weight of wire loop and sinker plus specimen in fluid.

For convenience, the above measurements are carried out in the order $A, C, B, D$. After the measurement of $C$, the wire loop and sinker are thoroughly cleansed either by allowing the fluid to evaporate or by rinsing with a volatile solvent.

Prior to the measurement of $D$, the specimen is slowly immersed into the fluid, care being taken to avoid dislodging the wire loop from the balance arm or changing the position of the glass rod. Sudden mechanical jolts to the balance system can disturb the measuring arm and result in a need for a lengthy recalibration procedure. 
Immediately after the specimen has been immersed in the fluid and after the vessel is set in place, the bucking voltage is adjusted to cancel out the signal from the electrobalance. A zero reading on the most sensitive scale of the recorder determines cancellation. As the fluid permeates into the specimen the change in buoyant force is recorded with time. If this change is larger than the full scale displacement of the recorder, then the bucking voltage is adjusted accordingly. When the buoyant force has reached a constant value which persists for a period of at least 8 hours, the DVM reading is recorded as the value of $D$.

4. The same specimen that has been immersed in the calibration fluid shall be dried and used again with the dielectric oil. The procedure as described above for obtaining readings of $A, B$, and $C$ is followed.

For the measurement of $D$ special attention must be given to the oil impregnation process and to the solubility of the specimen in oil. $0 i 1$ impregnation is monitored using the chart recorder. When a steadystate or near steady-state value of the buoyant force is reached, a preliminary calculation of the percentage of unfilled void volume shall be carried out using the equation given in $9 * 6$.

If there is a significant amount of unfilled void volume, then vacuum, temperature and pressure (if it is available) cycling shall be used in order to achieve the maximum degree of void filling. The cycling procedures which achieve the optimum are recorded for use in subsequent impregnation. After all the impregnation procedures are complete, the steady-state value of the DVM reading is recorded as the value of $D$.

5. Before a final calculation of the unfilled void volume is made, the solubility of the specimen in oil must be determined. To do this the calibration fluid is used as a washing medium after the specimen is removed from the oil. Since the calibration fluid mixes with the dielectric oil, it is possible to remove all of the oil from the pores by repeated washing and drying. Drying can be carried out either by evaporation at ambient room conditions or under vacuum. The weight of the specimen is measured after each wash-dry cycle until a constant weight is reached. If there is no difference between the original and final weight of the specimen the values of $(B-A)$ and $(D-C)$ can be used to calculate the unfilled void volume without any adjustment. However, if there is a specimen weight loss and it is smal1, less than $1 \%$, then the value of $(B-A)$ is lowered by the amount of weight loss before making the calculations in $9 * 6$. Also, for solubility less than $1 \%$, it can be assumed that the density of oil remains unchanged. If the solubility is larger than $1 \%$, then the specimen may be judged unsuitable for continued testing, and, if a calculation of the unfilled void volume is desired it may be necessary to remeasure the density of the oil.

\section{9 * 6 Calculations or Interpretations of Results.}

1. The density, specific volume, specific unfilled void volume, and the percentage of unfilled void volume are calculated from the two sets of values of $A, B, C$ and $D$. 
2. From the calibration fluid data, the specific volume and density of the porous tape specimen are obtained from the following:

$$
v_{s}=\frac{1}{d_{f}}\left[1-\frac{(D-C)}{(B-A)}\right]
$$

where

$v_{S}$ is the specific volume of the specimen,

$d_{f}$ is the density of the calibration fluid at the temperature of the measurement.

The density of the specimen, $\rho_{S}$, is

$$
\rho_{s}=1 / \nu_{S}
$$

3. From the measurements on the oil-immersed specimen, the specific volume of unfilled voids is calculated from the following:

where

$$
v_{v}=\frac{1}{d_{0}}\left[1-\frac{(D-C)}{(B-A)}\right]-v_{s}
$$

$v_{v}$ is the specific volume of unfilled voids.

$d_{0}$ is the density of the oil at the temperature of the measurement.

$v_{s}$ is the specific volume of the specimen.

The apparent density of the specimen in $0 i 1, \rho_{0}$, is calculated from

$$
\rho_{0}=d_{0}\left[\frac{B-A}{(B-A)-(D-C)}\right] \text {. }
$$

4. The percentage of unfilled void volume, $\% v_{v}$, is

$$
\% v_{v}=\left[\frac{\nu_{v}}{\nu_{v}+v_{s}}\right] \times 100 \%
$$

\section{$9 \star 7$ Report.}

The report shall contain the following information:

1. Name and location of laboratory,

2. Name of person responsible for the test,

3. Name of person performing the test,

4. Date of experiment,

5. Name and origin of material,

6. Specimen identification,

7. Name of calibration fluid,

8. Name of dielectric oil,

9. Temperature of experiment,

10. Density of calibration fluid at measurement temperature,

11. Density of dielectric oil at measurement temperature,

12. Values of $A, B, C$, and $D$ for calibration fluid,

13. Values of $A, B, C$, and $D$ for dielectric oil,

14. Strip chart recording of $\Delta W$ versus time,

15. Impregnation procedure to be used for conditioning specimens for tests requiring impregnation.

16. Calculation of $P_{S}, \nu_{s}, P_{O}, \nu_{v}$ and percent unfilled void volume. 
$9 \star 8$ Precision and Accuracy. In order to establish the precision and accuracy of this test, errors due to the instrument, temperature variation, different calibration fluids and different dielectric oils need to be considered. Such an extensive analysis requires many measurements and could not be carried out here. Thus, the overall precision and accuracy of this measurement is not known. The maximum uncertainty in the measurement of specific volume due to weighing errors alone was calculated to be $\pm 0.0004 \mathrm{~g} / \mathrm{cm}^{3}$.

Test 11. Shear modulus, Dry, $23^{\circ} \mathrm{C}$

$11 * 1$ Specimen Selection, Number, and Dimensions. The shear modulus measurement requires a sheet of material approximately $10 \mathrm{~cm} \times 20 \mathrm{~cm}$. This sheet is rolled into a tube $10 \mathrm{~cm}$ long and approximately $2 \mathrm{~cm}$ in diameter.

$11 * 3$ Apparatus. The apparatus for the measurement of shear modulus will be the same as that originally described by workers at Pirelli. This apparatus is described in Appendix B of Reference (14). For this test a sheet of material is rolled into a tubular shape and the starting edge and finishing edge are glued into place. One end of the tube is held fixed while the other is rotated. This shear has an angular moment in the direction normal to the plane of the tape surface.

$11 * 7$ Report. The report should contain the following:

1. Name and location of laboratory where tests were performed

2. Name(s) of persons performing the test

3. Complete identification of material tested

4. Dimensions of test specimen

5. Temperature of test

6. Resultant calculation of shear modulus

$11 * 8$ Precision and Accuracy. The precision and accuracy of this test has not been determined.

Test 12. Compression Modulus, Stack, Dry, $23^{\circ} \mathrm{C}$

$12 * 1$ Specimen Selection, Number and Dimensions, Specimens are stacks of diecut disks, $2.54 \mathrm{~cm}$ ( 1 inch) in diameter. Other diameter specimens can be used depending on the needs of the testing machine, but the diameter shal1 not be less than $1.5 \mathrm{~cm}$. A sufficient number of disks are cut and stacked to make a stack $1 \mathrm{~cm}$ high. Three separate specimen stacks shall be measured. The three stacks may be separate sample material or the disks of one stack may be rearranged and designated as another specimen stack. 
1. Testing machine - The testing machine shall be one of the following types:

a) A machine which is capable of applying a load increasing at a constant rate either in tension or compression;

b) A machine which operates at a constant rate of crosshead movement either in tension or compression.

2. Pressure posts - For the case of a testing machine operating in compression, the machine shall be fitted with two opposing cylindrical posts with plane and parallel faces. The diameter of these cylinders shall be the same and shall be equal to the specirnen diameter.

3. Interlocking c-grips - For the case of a testing machine operating in tesnion, the machine shall be fitted with two interlocking cgrips as shown in Figure 4-2. The opposing surfaces of the c-grips shall be plane and parallel and shall have a rectangular area larger than the area of the specimen.

4. Position Transducer - The pressure posts or the interlocking c-grip shall be fitted with a transciucer capable of indicating the relative position of the pair of posts or c-grips to a resolution of $2 \mu \mathrm{m}$ over a range sufficient to cover the motion resulting from the application of pressure. A linear variable differential transformer (LVDT) is shown in Figure 4-2.

5. Load indicator - The load-indicating mechanism shall be capable of showing the total load carried by the test specimen. This mechanism shall indicate the load with an accuracy of $1 \%$ of the indicated value. The accuracy of the testing machine shall be verified in accordance with ASTII E4.

6. Recording device - A recording device with enough sensitivity to record the limit of resulution of both the load indicator and the position transciucer shall be employed. This device can be a chart recorder or a data processing unit which converts the data to digital form.

7. Gauge blocks - The position transducer shall be calibrated in increments of $0.25 \mathrm{~mm}$ over the range of the specimen compression. Gauge blocks shall have thickness accurate to $\pm 1 \mu \mathrm{m}$.

\section{$12 \star 4$ Procedure.}

1. Place stack of film disks between pressure posts or interlocking c-grips, aligning the edges.

2. Bring posts or c-grips in contact with the film stack and apply small initial pressure.

3. Apply pressure increasing at a constant rate (approximately $3.71 \mathrm{~N} / \mathrm{sec}$ (50 lbs/ minute) for those machines so capable, or, apply pressure by decreasing crosshead separation at a constant rate). 


\section{To Tensile Testing Machine \\ or Weight-Pulley System}

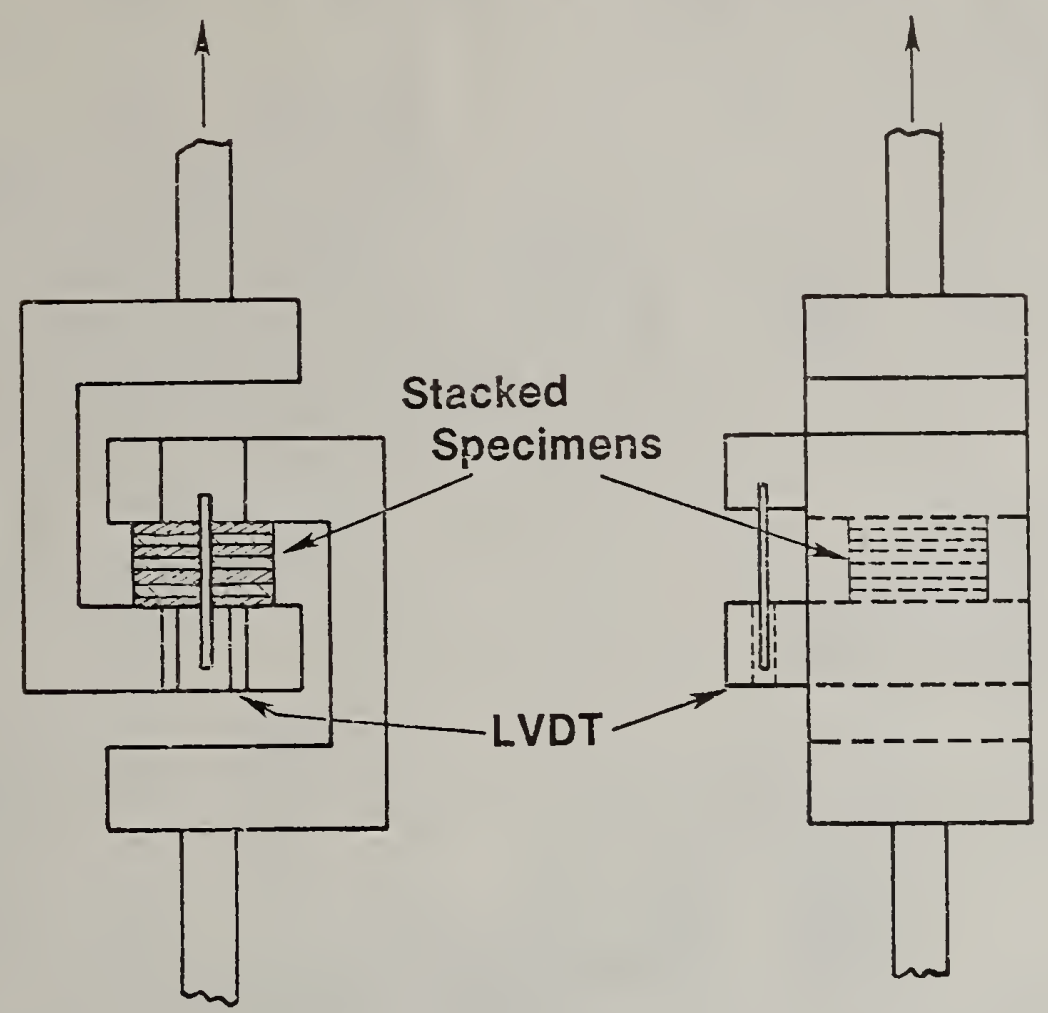

Front View

Side View

Figure 4-2. Suggested Grip Modification for Tests 12 and 16

4. Continue to apply pressure and collect output data until a maximum of $8.27 \times 10^{5} \mathrm{~N} / \mathrm{m}^{2}(120 \mathrm{psi})$ is reached.

5. Release pressure. Data as a function of decreasing pressure is not used.

6. Remove specimen without distrubing the alignment of the position transducer.

\section{$12 \star 5$ Precautions.}

1. Care must be exercised to see that the stack does not buckle under pressure. If buckling occurs, decrease the stack height.

2. The position transducer must remain in alignment so that its calibration remains effective. 


\section{$12 * 6$ Calculation or Interpretation of Results.}

1. Pressure on the specimen is obtained by dividing the load by the area of the specimen.

2. The thickness of the specimen, $t$, is equal to the separation between pressure posts or c-grips and is obtained from the position transducer data.

3. Using the recorded load and transducer data, a plot of pressure versus specimen thickness is made over the pressure range 0 to $8.27 \times 10^{5} \mathrm{~N} / \mathrm{m}^{2}(120 \mathrm{psi})$. On this plot, $t$ is plotted in the direction of decreasing $t$.

4. The slope of the pressure versus $t$ curve is obtained at five pressures:

$$
\begin{aligned}
& 1.38 \times 10^{5} \mathrm{~N} / \mathrm{m}^{2} \quad(20 \mathrm{psi}) \\
& 2.75 \times 10^{5} \mathrm{~N} / \mathrm{m}^{2}(40 \mathrm{psi}) \\
& 4.14 \times 10^{5} \mathrm{~N} / \mathrm{m}^{2}(60 \mathrm{psi}) \\
& 5.52 \times 10^{5} \mathrm{~N} / \mathrm{m}^{2}(80 \mathrm{psi}) \\
& 6.89 \times 10^{5} \mathrm{~N} / \mathrm{m}^{2}(100 \mathrm{psi})
\end{aligned}
$$

The slope at thickness, $t$, is calculated either by an automatic data processing technique or by graphical analjsis. It is expressed as:

$$
(\text { S1ope })_{t}=\left.\frac{\Delta\left(\frac{1 \text { load }}{\text { area }}\right)}{\Delta t}\right|_{t}
$$

The compression modulus $E_{C}$ at $t$ is given by

$$
E_{C}=\frac{\Delta\left(\frac{\text { load }}{\text { area }}\right)}{\Delta t / t}=t(\text { S lope })_{t}
$$

From the three specimens, three compression moduli are calculated at each of the five pressures. The average and standard deviation of $E_{C}$ at five pressures are calculated.

\section{$12 * 7$ Report. The report shall contain:}

1. Name and location of laboratory where tests were performed.

2. Name(s) of person(s) performing tests.

3. Date(s) of tests.

4. Complete identification of material tested.

5. Compression modulus calculated per $12 \star 6$.

$12 * 8$ Precision and Accuracy. The precision of the compression modulus measurement by this method should be $\pm 5 \%$. The accuracy of the measurement has not be determined (16). 


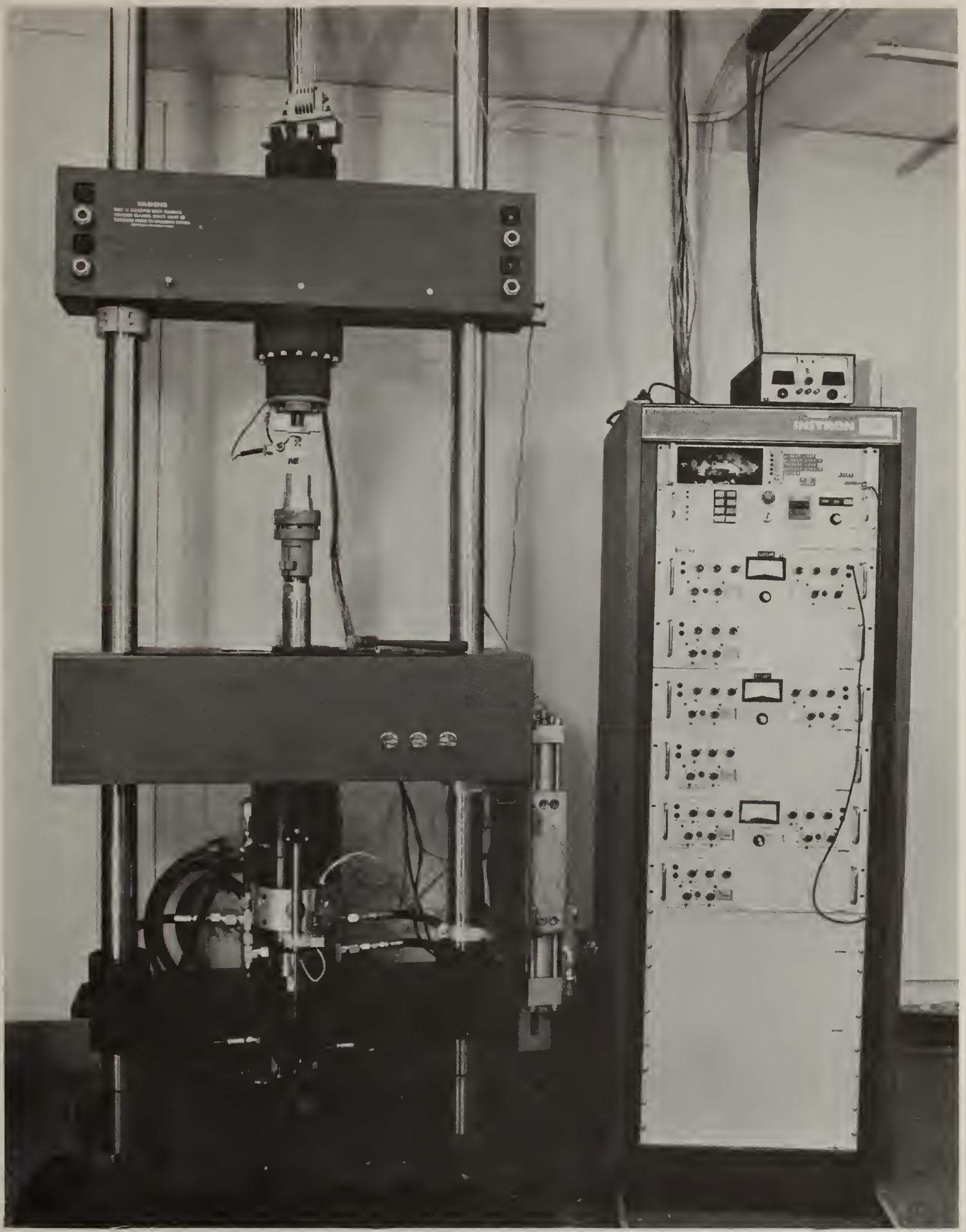

Figure 4-3. Testing machine used by Dr. R. W. Penn at the National Bureau of Standards to measure the compression modulus of a stack of tapes (Test Nos. 12 and 16). 


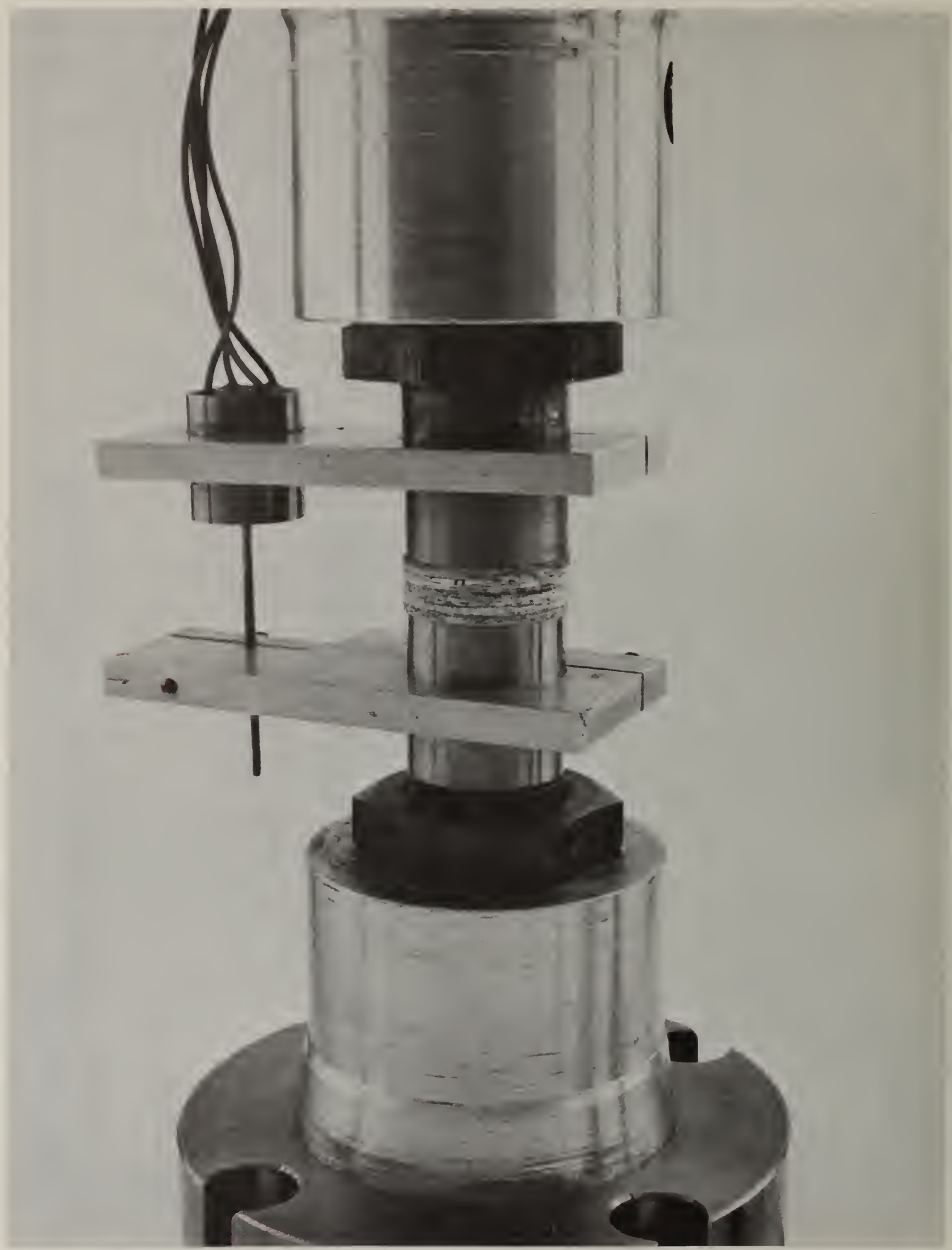

Figure 4-4. Stacked specimen in testing machine. The LnVT is seen mounted on the posts. This machine is operating in the compression mode, and does not require the c-grips shown in Figure 4-2. 
Test 14. AC Breakdown on Stack of Tapes in 011,23 and $120^{\circ} \mathrm{C}$.

$14 * 1$ Specimen Selection, Number and Dimensions. Specimen selection shall be the same as for Test 3, except that the number must be increaser to provide for stacking four pieces for each specimen, Ref. (17).

Test 15 . Stress-Strain in 0 il at 23,90 and $120^{\circ} \mathrm{C}$.

$15 * 1$ Specimen Selection, Number and Dimensions. The specimen length shall be $18 \mathrm{~cm}$ ( $7 \mathrm{in.})$. This is the same as for Test 19. The results of this test (Test 15) are to be compared later with those of Test 19: thus a standardized length is desirable.

$15 * 3$ Apparatus. The apparatus is the same as for Test 4 , with the addition of an $0 i 1$ and thermal jacket. Such chambers are commercially available, or they are easily assembled from standard laboratory apparatus. A sketch of a suggested design is shown in Figure 4-5.

\section{To Mechanical Testing Machine or Weight-Pulley System}

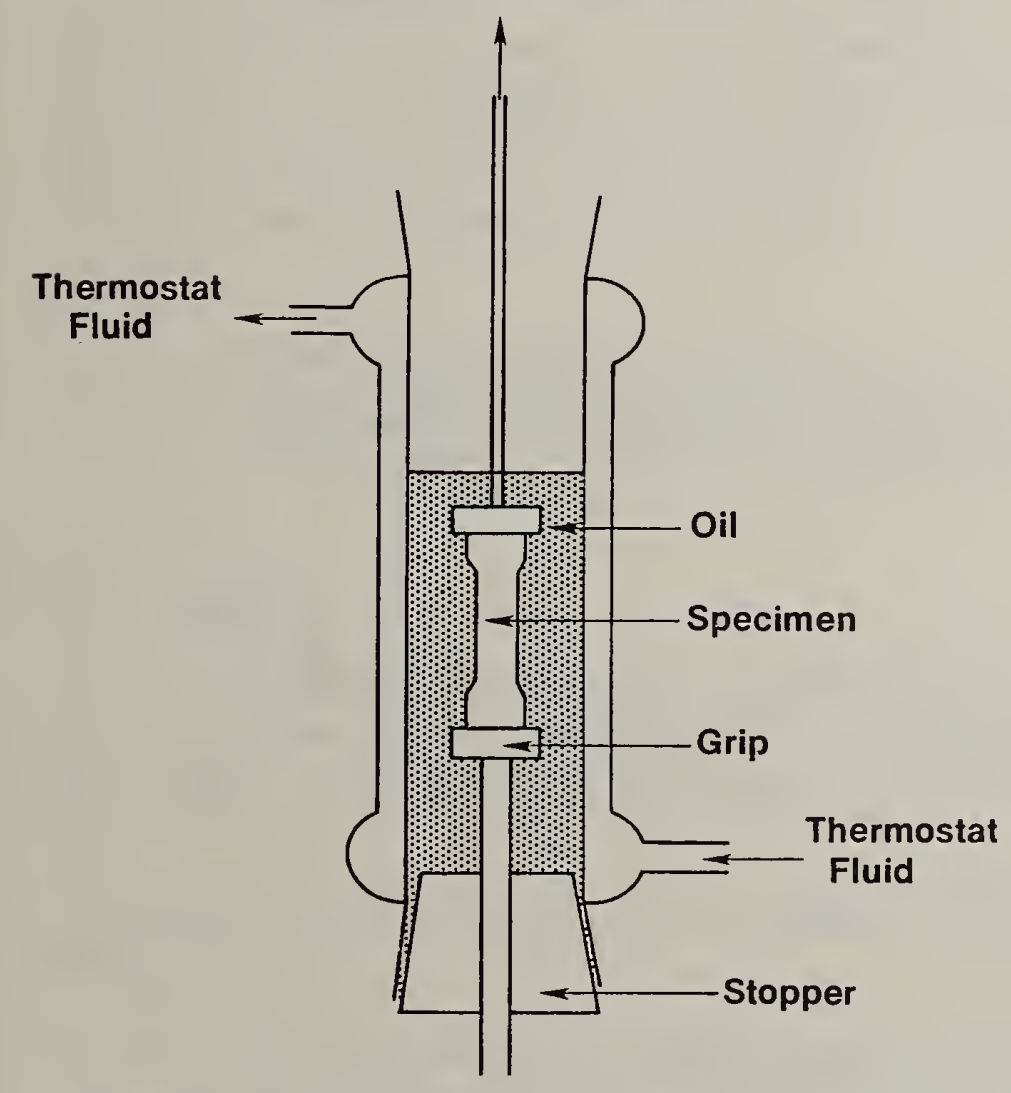

Figure 4-5. Suggested $0 i 1$ and Thermal Chamber for Tests 15 and 19 
Test 16. Compression Modulus on Stack in 0 il, $23^{\circ} \mathrm{C}$.

16 * 3 Apparatus. The apparatus shall be the same as for Test 12, except modified to provide for performing the test with the specimen immersen in oil. The vessel of Figure 4-5 can be used for this test.

16 * 4 Procedure. The procedure is the same as for Test 12, except that the specimen is immersed in oil before and during the test. 
Test 17. Swelling, Force, Stack, in $0 \mathrm{il}, 23 \mathrm{C}$.

$17 * 1$ Specimen Selection, Number and Dimensions. Prepare one specimen for each winding tension being tested. Each specimen consists of a roll of tape prepared by winding dry tape at constant tension on a 20-mm core until a build of 20-50 mm is reached. The width of the tape shall be 20-50 mm. The huild will depend on the cable diameter being simulated. At intervals during the winding, metal tabs, described below, are inserted in such a way as to extend entirely through the roll, and placed so that they are scattered with respect to a radius of the roll. Insert a tab approximately every $5 \mathrm{~mm}$ of build. The outer end of the tape is suitably secured so it cannot unrol1.

The tabs are pieces of $1 \mathrm{mil}$ stainless steel shim stock, 0.5 inch wide, with holes at one end for attaching a pulling line. It may be necessary to reinforce these holes. The length of the tabs should be onough greater than the width of the tape so that the tabs will extend completely through the roll and also allow room to attach the. pulling line.

$17 * 2$ Conditioning. The impregnation procedure of this test specimen may differ from that which was developed in test 9 , because the specimen is in the wrapped configuration. It is suggested that a buoyant force measurement be made with the specimen on the spool. The objective would be to calculate the apparent density in oil or the specific volume of unfilled voids. To do this, the equation of $9 * 6$ is used where

$A$ is the weight of the empty spool.

B is the weight of the spool plus wound tape.

C is the weight of the empty spool plus wire immersed in oil.

D is the weight the spool plus wire and wound tape immersed in 011.

\section{$17 * 3$ Apparatus.}

1. Specimen-winding apparatus. - A lathe, or equivalent, shall be used to wind the specimen coils. The lathe shall be capable of running at slow but steady speed, slow enough to permit insertion of the tabs without stopping.

A supply spool capable of paying off the tape at constant tension shall be used. Peference (14).

2. Tab-pulling device. - A support shall be provided capable of supporting the specimen by the core, with the tabs and pulling holes at the hottom. A cup 
of adequate size shall be provided, with means of attachment to one of the tabs at a time. (Weight is then added to the cup until the tab slides out of the coil).

3. Cup-weighing device. - A scale shall be provided capable of weighing the cup and its contents. (Contents are that which was just sufficient to pull the tab from the coil).

\section{$17 * 4$ Procedure.}

1. Wind specimens as per $17 * 1$

2. Impregnate specimens as per $17 * 2$

3. Measure and record the distance of each tab from the core (along a radius).

4. Hang the specimen by the core from the support described in $17 * 3$.

5. Attach the cup $(17 * 3)$ to one of the tabs.

6. Gradually, add weight to the cup by pouring into it water or lead shot. Arrange to catch the cup without spilling any of the contents when the tab slips out of the core. Stop adding weight when the tab slips out.

7. Weigh and record weight of cup and contents, identifying hy distance from core the tab pulled and weight required to pull it.

8. Repeat sters 3-7 for each remaining tab.

\section{$17 \star 5$ Precautions.}

1. Be sure that pull-out force is not affected by roughness or burrs at edge of the shim stock used for the tabs. If necessary, hone carefully to remove burrs.

2. Make sure the coil winds uniformly as the specimen is prepared. Ineven tape thickness from one edge to the other could produce a misshapen coil.

\section{$17 * 6$ Calculation or Interpretation of the Pesults.}

1. The wet coefficient of friction between the material under test and the metal tabs used must be known. This is determined in Test 18.

2. The swelling force at the radius of each tab is given by:

$$
F=\mu_{w} \phi r^{A}
$$

where $u_{w}$ is the wet coefficient of friction

$F$ is the force required to pull the tab

$A$ is the area of the tab in contact with the film coil

$\phi_{r}$ is the radial pressure in the film coil at radius $r$. 


\section{$17 * 7$ Report}

The report shall include:

1. Complete identification of the material under test and oil used.

2. Name and location of laboratory performing the test.

3. Name of person(s) performing the test.

4. Date(s) of testing.

5. A table giving the radial distance from the core of each tab, the force required to pull the tab, the radial pressure calculated for each tab.

6. A plot showing radial pressure as a linear function of distance from the core.

\section{$17 * 8$ Precision and Accuracy}

1. The accuracy of this test is not established.

2. The plot of radial pressure vs. distance from core will reveal to some degree how precisely the radial pressure can be determined.

Test 18. Wet Coefficient of Friction, $23^{\circ} \mathrm{C}$.

$18 * 3$ Apparatus. The apparatus which was used to obtain the dry coefficient of friction (Test 5 ) is used here also. The apparatus is immersed in oil bv filling the pan shown in Figure $4-1$.

18 * 4 Precautions. Care should be taken so that slippage of the oil-impregnater specimen in the grip does not occur.

Test 19. Stress-Strain at $23^{\circ} \mathrm{C}$, After Aging "Inder "echanical and Flectrical Stress in Vacuum-Treated 0 il at $120^{\circ} \mathrm{C}$.

$19 * 1$ Specimen Selection, Number and Dimensions. The specimens shall consist of $18 \mathrm{~cm} \times 18 \mathrm{~cm}$ square sheets. For materials which are isotropic, one sheet for each aging time period shall be used. For anisotropic materials, two sheets for each time period shall be used. Since there are two time periods for aging, 4 weeks and 32 weeks, two sheets of isotropic material and four sheets of anisotropic material are needed. After a sheet specimen has been aged in oil at an elevated temperature, the sheet is cut into five $18 \mathrm{~cm}$ length specimens so that mechanical testing in accordance with ASTM D882-75b can be carried out. For anisotropic materials, ten tensile specimens, five normal and five parallel to the axis of anisotroy, shall be used. 
1. Specimen Stress Unit - This unit shall hold a specimen under mechanical and electrical stress during aging. A design for this unit is shown in Figures 4-6 and 4-7. A specimen is held extender hy an extension plate inserter! between the grips. The size of the stress unit shall be large enough to accommodate the $18 \mathrm{~cm} \times 18 \mathrm{~cm}$ square sheet. An electric field is placer across the specimen using the high-voltage electrode which is $10 \mathrm{~cm}$ in diameter situated in the center of the stress unit.

2. High yoltage AC Source - This voltage source shall be capable of applying a field of $3 \mathrm{kV} / \mathrm{mm}$ across the specimen in the stress unit.

3. Temperature Control 0il Bath - a bath capable of maintaining the stress unit in a dielectric oil at $120^{\circ} \mathrm{C}$ for 32 weeks shall be used.

4. Dielectric 0il - The appropriate dielectric oil shall be vacuum treated and dried before being used in the aging test.

5. Testing machine - A testing machine as described in ASTM D882-75b, Section 5 , shall be used.

6. Other apparatus of ASTM D882-75b, Section 5, shall he used as needed.

\section{Assernbled Stress Unit}

\section{High Voltage Electrode}

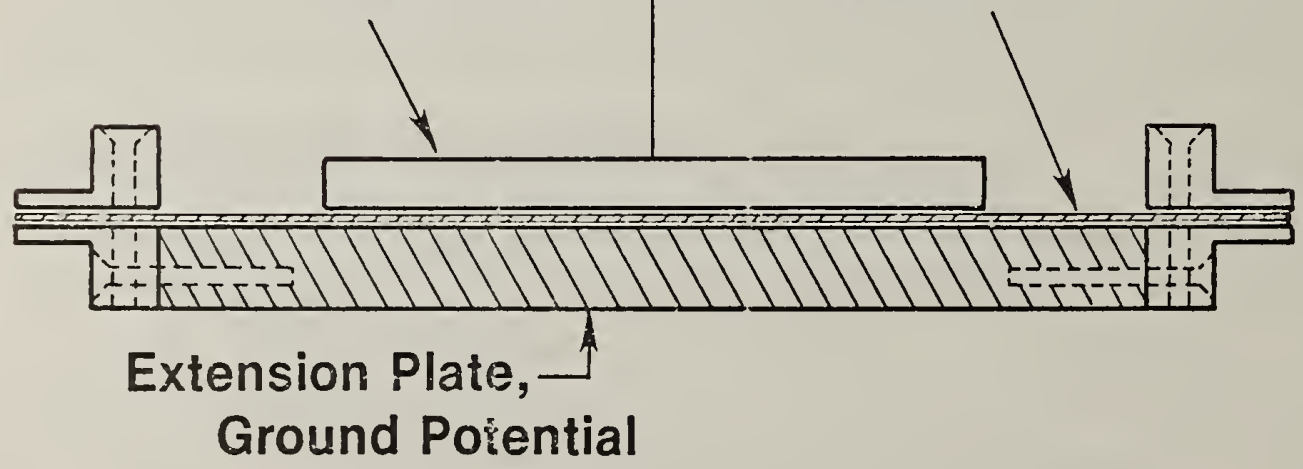

Figure 4-6. Stress Unit for Tests 19 and 20 


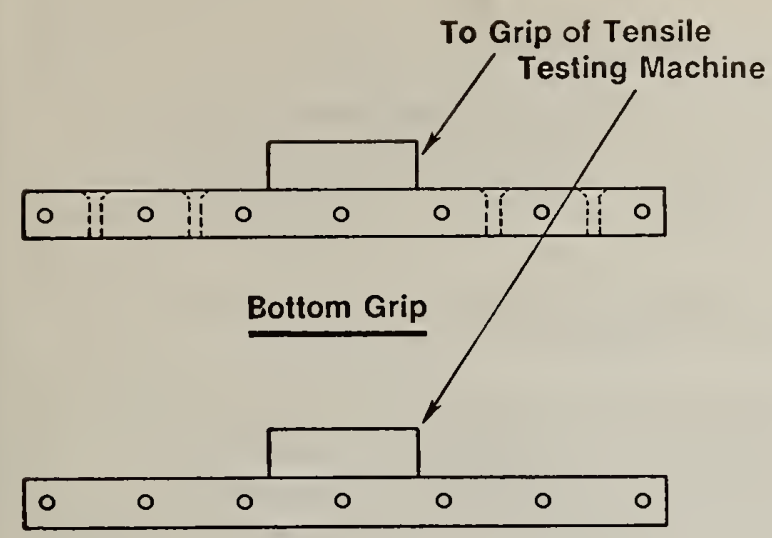

Top Grip

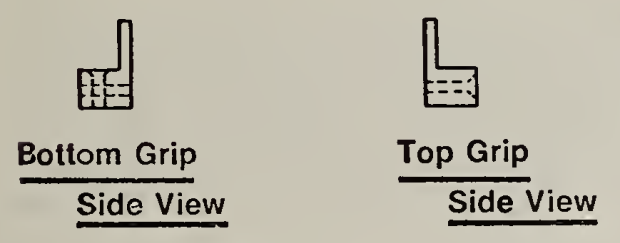

Figure 4-7. Grips for Stressing Material for Tests 19 and 20

\section{$19 * 4$ Procedure.}

1. The specimen is placed in the grips of the stress unit with a distance $\&$ between the grips.

2. The grips are attacher to the testing machine and the specimen is given a strain of $1 \%$.

3. The specimen is held at $1 \%$ strain in the testing machine while the extension plate is placed in position as in Figure $\Delta_{i}-6$. The extension plate has a dimension equal to $l+0.01 l$, thus holding the specimen at $1 \%$ strain.

4. The assembled stress unit is placed in oil and the specimen is permeated with oil in accordance with the procedure developed in test 9. For anisotropic materials two specimens shall be used.

5. After oil impregnation, the high voltage electrode is placed in position.

6. The $0 i 1$ bath is brought to $120^{\circ} \mathrm{C}$ and the high voltage is applied.

7. At the end of four weeks, the high voltage is turned off, the specimen is brought to room temperature and removed from the $0 i 1$ bath.

8. For the tensile tests, the sheet is cut into five specimens having a gage length of 13-15 cm. The shape of the specimens will be in accordance with ASTM D 882-75b. For anisotropic materials ten tensile specimens, five in each of the perpendicular directions, are needed. 
9. The dimensions of the specimen are accurately measured.

10. Mechanical testing is carried out in $0 i 1$ at room temperature following the procedure described in test 110.15 . The specimens shall be stressed in the testing machine to yield or fracture, while load and extension data are obtained.

11. A calculation of the tensile modulus and strength is made in accordance with $19 * 6$.

12. Considering the results of the calculation of modulus and tensile strength, a iudament is made whether or not to continue with a 32week experiment, by applying the following criterion: If there is a significant difference between the physical properties as measured after four weeks and those measured in Test 15 , it is concluder that material deterioration has begun and further testing is not warranted.

In order to test for a significant difference between the data of Test 15 and Test 19 , a statistical test, a two-sided t-test at the $90 \%$ confidence level, is used. This test, which is described in (18), consists of using the estimated standard deviations from the two sets of data and a tabular value of $t$ to compute a test criterion.

We define

$\bar{X}_{15}$ is the average value of the measurements from Test 15 ,

$\bar{X}_{19}$ is the average value of the measurements from Test 19,

$S_{15}$ is the estimated standard deviation of the values from Test 15 ,

$\mathrm{s}_{19}$ is the estimated standard deviation of the values from Test 19 ,

$U$ is the computed test criterion,

If $\quad\left|\bar{X}_{15}-\bar{x}_{19}\right|>U$

then, it can be concluded that $\bar{X}_{15}$ and $\bar{X}_{19}$ are significantly different. The value of $U$ is computed from (18)

where

$$
U=\operatorname{ts} p\left(\frac{m_{15}+m_{19}}{m_{15} m_{19}}\right)^{\frac{1}{2}}
$$

$t \quad$ is the statistical t-distribution,

$m_{15}$ is the number of measurements of the mechanical property from Test 15,

$m_{19}$ is the number of measurements of the mechanical property from Test 19, 
and

$$
s_{p}=\left[\frac{\left(m_{15}-1\right) s_{15}^{2}+\left(m_{19}-1\right) s_{19}^{2}}{m_{15}+m_{19}-2}\right]^{1 / 2} .
$$

When $m_{15}=5$ and $m_{19}=5, t=1.86$ at the $90 \%$ confidence level and " $=1.18 \mathrm{~s} p$.

13. For the 32-week test, the procerlure in steps 1 thru 10 is followed, except that the specimens are ager at $1200 \mathrm{C}$ in oil for 32 weeks.

14. The results of the 32-week test are comparen with the results of Test 15. A check for significant differences is marle.

Test 20. Impulse and AC, Rreakdown at $23^{\circ} \mathrm{C}$, After Aging IInder Mechanical and Electrical Stress in 1/acuum-Treater $0 i 1$ at $1200 \mathrm{C}$

$20 * 1$ Specimen Selection, Number and Dimensions. The specimen size shall he the same as for Test $19,18 \mathrm{~cm} \times 18 \mathrm{~cm}$ square sheets. The number of specimens shal1 be five each for the impulse and ac breakdown tests. Since there are two time periods for aging, 4 weeks and 32 weeks, a total of twenty sheets are needer.

$20 * 3$ Apparatus. The apparatus of Tests 13 and 14 wi11 be needed in order to carry out the impulse and ac breakdown tests after the specimens have been aged in $0 i 1$ at $120^{\circ} \mathrm{C}$. In addition, items 1,2 and 3 of $19 * 3$, the stress unit, a high voltage ac source, and temperature-controlled oil bath(s) will be needer.

The dielectric oil shall be vacuum treated and tried hefore using it as an aging medium at $120^{\circ} \mathrm{C}$.

\section{$20 * 4$ Procedure.}

1. The aging procedure shall be the same as for $19 * 4$, steps 1 thru 7 , i.e. the specimen sheets are placed in the stress unit and aged in oil under electrical stress at $120^{\circ} \mathrm{C}$.

2. After the 4-week immersion period is finished, the specimens are used to measure impulse and ac break lown at room temperature. For impulse breakdown, the procedure followed is the same as 13 * 4 for measurements at $230 \mathrm{C}$. For ac breaknown, the procedure followed is the same as $14 * 4$.

3. Calculations of impulse and ac breakdown are carried out accorting to $13 * 6$ and $14 * 6$ respectively.

4. The 32-week test is carried out only if there is no significant difference between the results from the 4-week tests and the results of Tests 13 and 14. To test for significant difference, the procedure outlined in $19 * 4$ regarding the application of the twosided t-test, is followed (18). 
5. If there is no significant difference between the results of the 4-week test and the results of Tests 13 and 14, then the 32-week test is carried out by repeating steps 1 thru 3 ahove.

6. The results of the 32-week test are compared with the results of Tests 13 and 14. A check for significant differences is made. 
table 4.1. Three.phase testing program

\begin{tabular}{|c|c|c|c|c|c|c|c|c|}
\hline PHASE 1 & 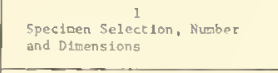 & 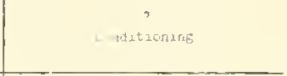 & $\stackrel{3}{\text { Apparatus }}$ & $\stackrel{4}{\text { Procedure }^{2}}$ & $\begin{array}{l}5 \\
\text { Precauctions }\end{array}$ & $\begin{array}{l}5 \\
\text { Calculation or Tnterpreceation } \\
\text { of Resules }\end{array}$ & $\underset{\text { Report }}{7}$ & Prectstan and acecuracy \\
\hline 1. Dielectric Constant & ASTM D 2305-72, Sec. 42.1 & Coveres under procerture & 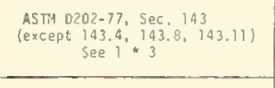 & 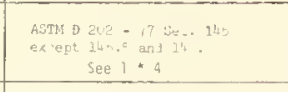 & ASTM D 150-74, Appendix A3 & $\begin{array}{l}\text { ASTM o } 150-74 \text {, table } 1 \\
\text { accordAnB to elecectrodes used. }\end{array}$ & 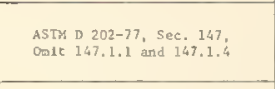 & ASTM D D 150-74, Sec. 6.5 \\
\hline 2. Loss Tangent & ASTA D 2305-72, Sec. 42.1 & Coveré under procedure & ASTM $0202-77$ & 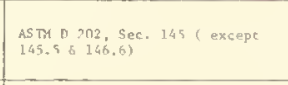 & ASTH O 150-74, Appendix A3 & $\begin{array}{l}\text { Astid D 150-74, Table } 1 \text {, } \\
\text { according to electrodes used. }\end{array}$ & 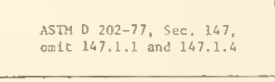 & ASTM D $150-74$, Sec. 6.5 \\
\hline 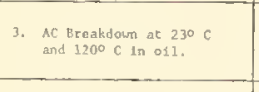 & 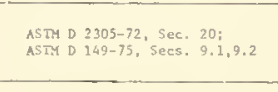 & $\begin{array}{l}\text { Impregnate } \\
\text { See } 3 * 2\end{array}$ & 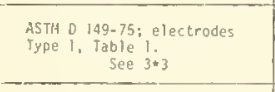 & $A=14$ D D 214t - is & $\begin{array}{c}\text { ASTM D 2305-72, Secs, 18.2, 20. } \\
\text { See } 3.5\end{array}$ & 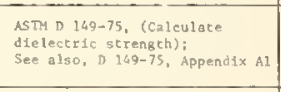 & ASTM D 2305-72, Sec. 24 & See $3 * 8$ \\
\hline 4. Stress-5sratin at $23^{\circ} \mathrm{C}$, dry & ASTM D Q882-75b, Seco. 6,3 & ASTA D G19-61 (1997) & ASTT D 882-75b, Sec. S. & ASTM D 883-756, Sees. 9, 20 & 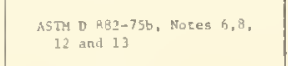 & ASTM D 882-75b, Sec. 11. & ASTM D 882-75b, Sec. 12. & $\begin{array}{l}\text { Assms D D82-75b, Secs. S.6. } \\
10 \text { and 11. }\end{array}$ \\
\hline $\begin{array}{l}\text { 5. Coeffictenc of Static } \\
\text { Fitction, Dry } 23^{\circ} \mathrm{C}\end{array}$ & $\begin{array}{l}\text { Ref. }\left(\frac{133)}{\text { See } 5.11}\right. \\
\text { S }\end{array}$ & ASTH D 61R-61 (1977) & $\begin{array}{l}\operatorname{Ref} \cdot\left(\frac{13}{3}\right) \\
\text { See } 5 * 3\end{array}$ & $\begin{array}{l}\text { Ref. } \\
\text { see } \\
5 \neq 4\end{array}$ & 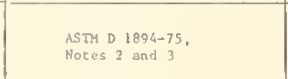 & ASTA D 1894-75, Sec. 10 & ASTY D 2894-75, Sec. 11 & ASTM D 1894-75, Sec, 10 \\
\hline $\begin{array}{l}\text { 6. Solvobiticy at } 23,906 \\
\text { 220 C }\end{array}$ & $\begin{array}{c}\text { AsTd D 1239-55(1971), Sec, } 5 \\
\text { See Text, Sec. } 6 \\
\end{array}$ & $\begin{array}{l}\text { Impregnate } \\
\text { See } 3 * 2\end{array}$ & 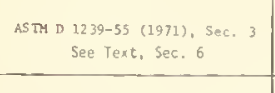 & See Text, Sec. 6 & ASTM D 1239-55(1971), Note 4 & ASTM D 1239-55 (1971), Sec. \& & ASTM D 1239-5S (1971), Sec. 9 & See Text, Secs. 5 and 5 \\
\hline 7. Sor tening Teaperature & ASTM o 1637-61 (1976), sec.4. & ASRA D 1637-61 (1976), sec. S. & ASTM D $1637-61(1976)$, Sec. 3. & ASTM D $1637-61$ (1976), Sec. 6 & $\begin{array}{l}\text { AsTM } 01037-61(1976), \\
\text { Sores } 6,8 \text { and } 11 .\end{array}$ & ASTM D 1637-61 (1976), Sec. 7 & ASTTA D 1637-61 (19976), See. \& & 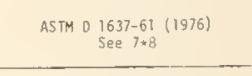 \\
\hline 8. Yelting Tesperature & ASTM D $3418-75$ & ASTA D 627-61 (1977) & ASTM D 3418-7s, Scc. 7 & 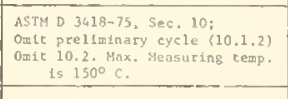 & ASTM D 3418-75, Sec. 6. & ASTTA D 3418-75, Sec. 10. & ASTM D 3418-75, See. 11. & 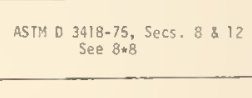 \\
\hline 9. Degree of Void Et11ing & $\begin{array}{l}\text { See Text, sec. S. } 5 \text {. } \\
\text { Specimen Preparation }\end{array}$ & ASTA D 618 -612 (1997) & $\begin{array}{l}\text { See Text. Sec. Ss, } \\
\text { Experimental Apparatus }\end{array}$ & See $9 * 4$ & Covered under Procedure & See $9 * 6$ & See $9 * 7$ & See $9 \cdot 8$ \\
\hline 10. Dirimensional Unifornity & ASTH D $374-74$ & ASTM D $678-61$ (1977) & ASTY D $374-74$ & $\begin{array}{l}\text { ASTTA } 0.374 .5 \mathrm{sec} .6 \\
\text { Sec. } 6.36 \text { 6.4 not appl Licabble }\end{array}$ & ASTM D $374-74$ & $\begin{array}{l}\text { Calculace aver ase and est thated } \\
\text { stendard devitation }\end{array}$ & ASTM D 374-74, Sec. 7 & ASTM D 374-74, Seess. 4,5 \\
\hline 11. Shear Hodulus, Dry, $23^{\circ} \mathrm{C}$ & See $11 * 1$ & ASTM 0 618-61 (1977) & $\begin{array}{c}\text { Refs. } \\
\text { See } 11+3\end{array}$ & 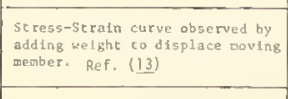 & Refs. $(12,13)$ & 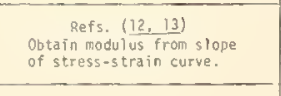 & See $11 \cdot 7$ & See $11+8$ \\
\hline 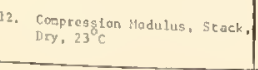 & See 12.1 & $\begin{array}{l}\text { ASTM D } 618-61(1997) \text {, and } \\
\text { ASTSA D 1994-75, sec.6 }\end{array}$ & See $12 * 3$ & See $12 * 4$ & See $12+5$ & See $12+6$ & See $12 * 7$ & See $12 \cdot 6$ \\
\hline
\end{tabular}


TABLE 4.1, continued

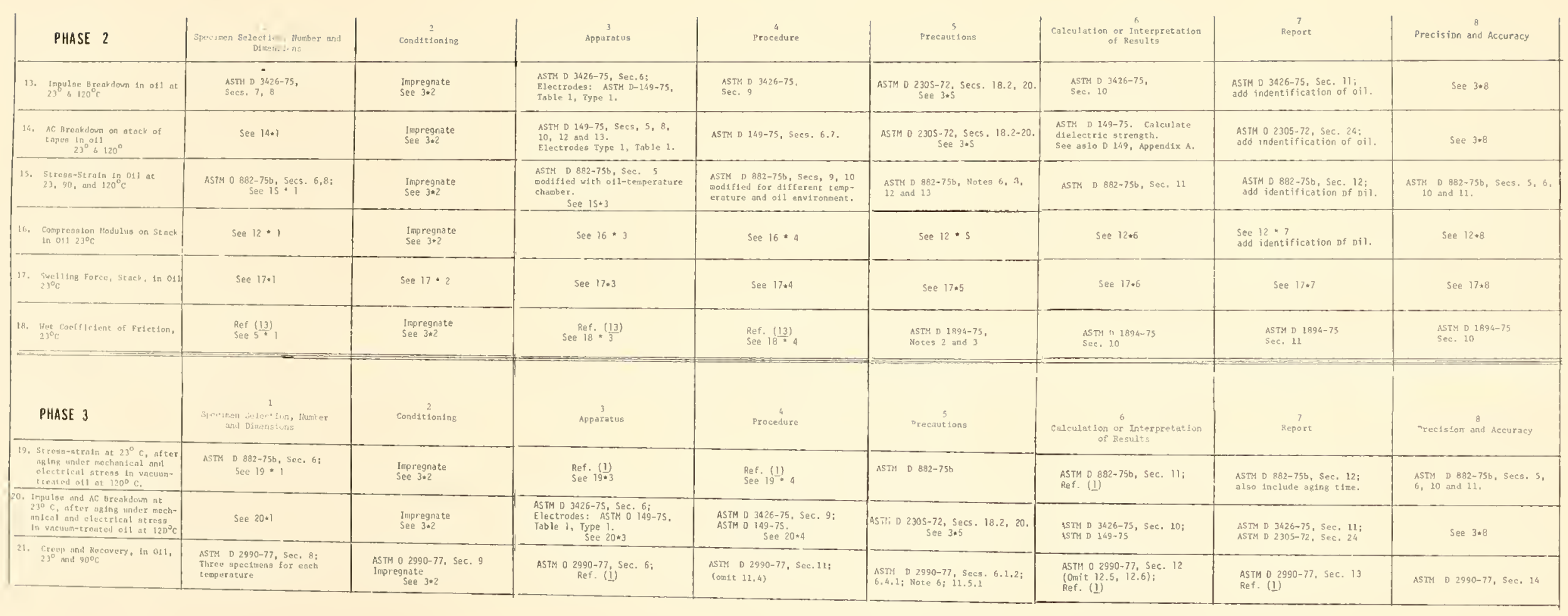

$4-26$ 
Section 5

DEGREE-OF-VOID-FILLING TEST

In this test, measurements are made for the purpose of calculating the amount of void volume of a specimen that remains unfilled by the dielectric oil. The experiment consists of measurements of the buoyant force on a porous tape immerser successively in two fluids; one a calibration fluid and the other a dielectric oil. The calibration fluid must satisfy three criteria:

- It must efficiently permeate the polymer material unter investigation, including closed (encapsulated)voids.

- It must not dissolve the polymer at room temperature.

- It must be a volatile liquid which mixes with the dielectric oil.

Having chosen a suitable fluid, it is assumed that the voids of an immersed specimen are entirely filled by it. From a knowledge of the density of the calibration fluid, the true specific volume of the polymer is calculated and then comparen to an apparent specific volume obtained from the buoyant force measurement of the specimen immersed in oil. The difference in the two specific volumes is proportional to the unfilled void volume.

\section{CALCULATION OF UNFILLED VOID VOLUME}

C.ASE 1: No Swelling, No Solubility

To analyze the experiment, we consider the simple case in which swelling and solubility do not occur. The weight of the specimen in the calibration fluid, $W_{f}$, is given by

$$
w_{f}=w_{s l}-v_{m f} d_{f}
$$

where the subscript $f$ refers to the calibration fluid, $V_{m f}$ is the volume occupied by polymer material, $d_{f}$ is the density of the calibration liquid, and $W_{s l}$ is the weight of the sample in air. The buoyant force is $-V_{m f}{ }_{f}$. 
For the polymer tape in oil experiment, another specimen may be used. The weight of the specimen in oil, $W_{0}$, is

$$
W_{0}=W_{s 2}-V_{m o} \lambda_{0}-V_{v_{0}} d_{0}
$$

where the subscript o refers to the oil, "mo is the volume of the specimen occupied by polymer, $\mathrm{A}_{0}$ is the density of oil, "vo is the volume of unfilled voids, and "W? is the weight of the specimen in air.

From Eq. 5-1, the specific volume of the speeimen, $v_{s}$, is obtained hy dividing thru by 1 s 1 ,

$$
v_{s}=\frac{1}{d_{f}}\left(1-\frac{w_{f}}{w_{s} 1}\right) .
$$

It is assumed that

$$
\frac{v_{m f}}{W_{s 1}}=\frac{v_{m o}}{W_{s 2}}=v_{s} \text {. }
$$

A rearrangement of Eq. 5-2 yields the specific volume of unfilled voids in oil, $v_{11}$ :

$$
v_{v}=\frac{v_{v_{0}}}{W_{s 2}}=\frac{1}{d_{0}}\left(1-\frac{W_{0}}{W_{s 2}}\right)-v_{s} \cdot
$$

The percentage of unfilled void volume is

$$
\frac{v_{v}}{v_{v}+v_{s}} \times 100
$$

Case 2: Swelling Occurs, But No Solubility

We consider now the case in which the specimen swells but there is no solubility. Generally, swelling can be caused by both the calibration fluid ant the oil. If the density of the swelling liquid which is incorporated in the polymer matrix is the same as the density of the liquid in the free state, then swelling will have no influence on the buoyant force, i.e. the fluid in the polymer exactly displaces itself and does not contribute to the buoyant force. In the analysis below, the following symbols are used: 


$$
\begin{array}{ll}
W_{s}= & \text { weight of specimens in air. } \\
M_{s f}= & \begin{array}{l}
\text { weight of swelling calibration fluid incorporated in the matrix of } \\
\text { the swelled polymer. }
\end{array} \\
V_{s f}= & \begin{array}{l}
\text { volume of the swelling fluid which is incorporated in the matrix of } \\
\text { the polymer. }
\end{array} \\
V_{m f}= & \text { volume occupied by polymer material, specimen in calibration fluid. } \\
W_{f}= & \text { weight of specimen in the calibration fluid. }
\end{array}
$$

As with Eqs. 5-1 and 5-6, we assume that the calibration fluid permeates effeciently and fills all the void volume. The weight of the swelled specimen in the fluid is

$$
w_{f}=w_{s}+M_{s f}-V_{m f} d_{f}-V_{s f} d_{f} .
$$

The volume $V_{s f}$ can be expressed as $M_{s f} / d_{s f}$ where $M_{s f}$ and $d_{s f}$ are the weight ant density of the swelling fluid incorporated in the polymer. Dividing thru by "! s we obtain.

$$
\frac{w_{f}}{w_{s}}=1+\frac{M_{s f}}{w_{s}}-\frac{V_{m f}}{w_{s}} d_{f}-\frac{M_{s f}}{W_{s}} \frac{d_{f}}{d_{s f}}
$$

where $\frac{V_{m f}}{W_{s}}=v_{s}$, the specific volume of the specimen. The ratio $M_{s f} / W_{s}$ will be called the fraction of swelling fluid, $F_{s f}$. Eq. 5-8 becomes

$$
\frac{w_{f}}{w_{s}}=1-v_{s} d_{f}+F_{s f}\left(1-\frac{d_{f}}{d_{s f}}\right) \text {, }
$$

where $w_{f}, w_{s}$ and $d_{f}$ are measured quantities. If $d_{f}=d_{s f}$, then Eq. 5-9 reduces to Eq. 5-1.

\section{Testing the Hypothesis}

In order to test the hypothesis that swelling does not influence the buoyant force, two observations are necessary: one in which no swelling occurs, and the other in which significant swelling occurs. The proposed test is to determine the specific volume of the specimen from Eq. 5-3 using a non-swelling liquid such as water, ant then to compare with the result obtained using a swelling fluid and Eq. 5-3. The result will indicate the effect of swelling on buoyancy and whether or not it can be assumed that $d_{f}=d_{s f}$. This test need not involve a porous polymer, and in fact it is easier to use a solid film. Two specimens were used: a solid film of polyethylene and a sheet of cross-linked rubber. 
In our first experiment the density of a crosslinked rubher was measuren in water. No swelling was detected and the density at $22.6^{\circ} \mathrm{C}$ was $0.9238 \mathrm{~g} / \mathrm{cm}^{3}$. The specimen was dried and then used in a buoyant force experiment using decane. Initally, this rubber specimen lost about $4 \%$ of its :veight in decane, but subsequent trying and reimmersion in decane caused no observable change in weight. 1t this point the specimen was immersed in decane and found to swell by $20 \%$. The rensity in recane was calculated to be $0.9253 \mathrm{~g} / \mathrm{cm}^{3}$, or an increase of $0.16 \%$ over that measured in water.

Next, a solid film of branched polyethylene was used. Its density, as measured by the buoyant force in water, was found to be $0.3262 \mathrm{~g} / \mathrm{cm}^{3}$ at $23.0^{\circ} \mathrm{C}$. In heptane, the density at $23.0^{\circ} \mathrm{C}$ was $0.9270 \mathrm{~g} / \mathrm{cm}^{3}$, or an increase of $0.09 \%$ over the density in water. The swelling was too small to detect by measurement of the thickness. The specimen was weighed in air and found to have increaser in weight by $6.6 \%$, due to retained heptane.

\section{Result}

Table 5-1 summarizes the results of these measurements.

TABLE 5-1

EFFECT OF SWELLING ON DENSITY

\begin{tabular}{|c|c|c|c|c|}
\hline Specimen & Temp. & Density $\left(\mathrm{g} / \mathrm{cm}^{3}\right)$ & $\% \Delta$ & Degree of Swelling \\
\hline \multirow[t]{3}{*}{ Rubber } & $22.6^{\circ} \mathrm{C}$ & $0.9238\left(\mathrm{H}_{2} \mathrm{O}\right)$ & & none \\
\hline & & & $0.16 \%$ & \\
\hline & & 0.9253 (decane) & & $20 \%$ \\
\hline \multirow[t]{2}{*}{ Polyethlyene } & $23.0^{\circ} \mathrm{C}$ & $0.9262\left(\mathrm{H}_{2} \mathrm{O}\right)$ & & none \\
\hline & & 00070 (hontane) & $0.09 \%$ & \\
\hline
\end{tabular}

a The thickness change was too small to measure. Weighing in air revealed that the polyethylene retained $6.6 \%$ heptane by weight. 
Because swelling has such a small effect on the buoyancy measurements, this effect can be neglected in subsequent measurements, except where precision greater than $0.1 \%$ is requirer.

EXPERI:MENTAL APP@RATIIS

\section{The Electrobalance}

The equipment which was used for the buoyancy measurements is a Cahn Rf nutomatic Electrobalance, shown in a schematic diagram in Figure 5-1. In this instrument the balance arm is connected to a coil which can rotate in a magnetic field. The current through the coil necessary to maintain the coil in a stationary position is proportional to the weight on the balance arm. The resolution of the instrument is

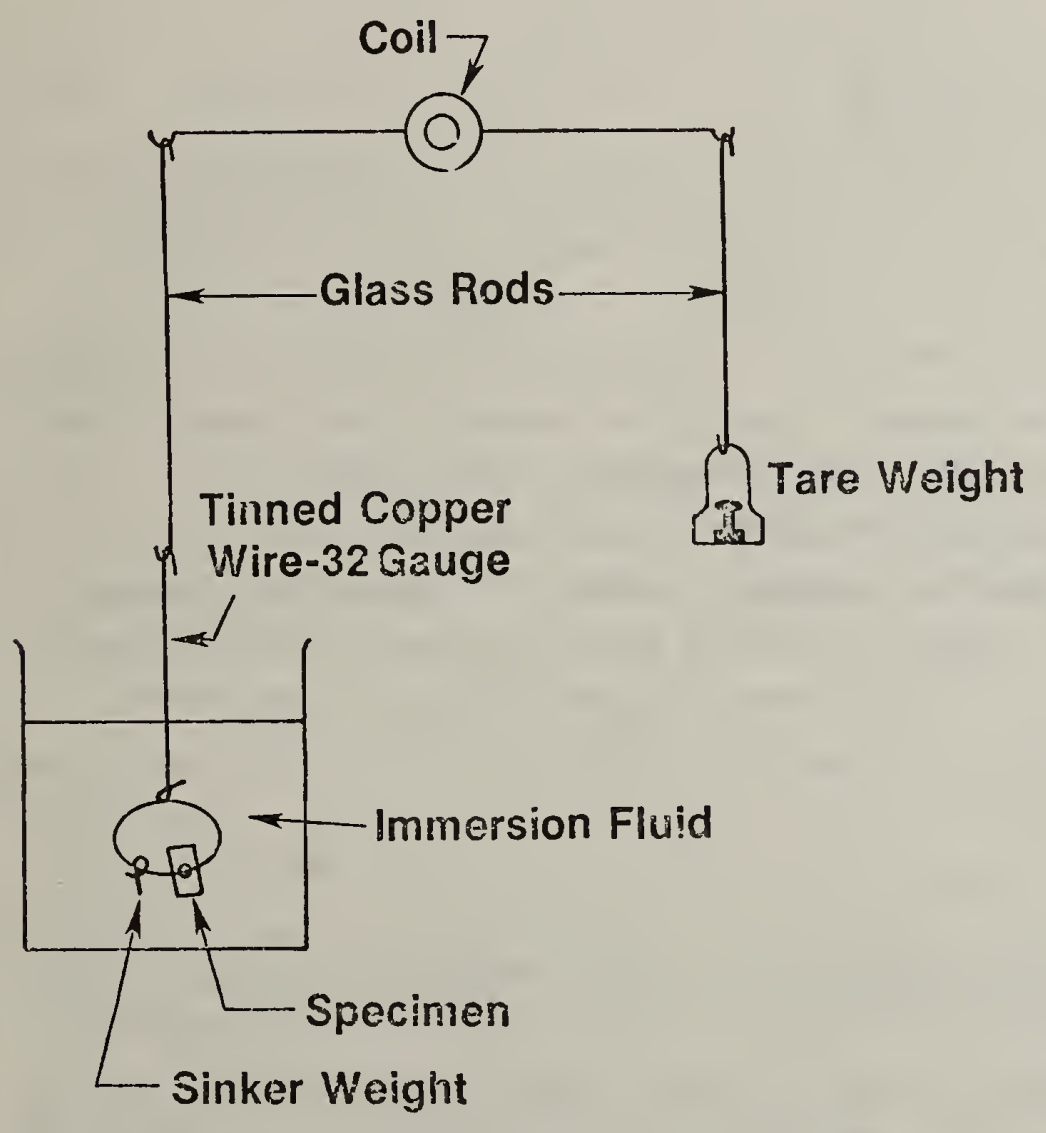

Figure 5-1. Schematic Diagram of S,ahn RG Automatic Flectrobalance 
$10^{-6} \mathrm{gm}$. The overall range of the electrobalance is only $\pm 100 \mathrm{mg}$ about zero or $200 \mathrm{mg}$ total. A counterbalance arm is provided for a tare weight which must be used to balance out most of the weight on the measuring arm but allow for the 100 mg swing about zero. Both the tare weight and the wire loop for the specimen are connected to the balance arms by thin glass rods. This isolates electric charges on the tare weight or specimen from the electrobalance circuitry. The wire loop, on which the specimen is threaded, is a 32-gauge tinned-copper wire. Also hooked on the wire is a sinker weight, a small piece of 20-gauge nichrome wire which keeps the specimen submerged in those cases when it would otherwise float on the liquid. For these experiments, the 32-gauge wire loop weighs approxinately $3 \mathrm{mg}$ and the nichrome sinker weighs approximately $100 \mathrm{mg}$.

Although it is not shown in Figure 5-1, the entire electrobalance system is enclosed in a vacuum vessel. This feature was utilized in several experiments described below.

\section{The Detecting and Recording Instruments}

The current signal from the electrobalance is converted to a voltage which is applied to two detecting instruments, a digital voltmeter and a potentiometric recorder. A block diagram is shown in Figure 5-2. The change in buoyant force with time is detected using the recorder. At the input to the recorder, a bucking voltage or a zero suppression device is used to cancel most of the signal so that changes in the electrobalance signal can be recorded on the most sensitive scale of the recorder ( $1 \mathrm{mv}$ full scale). The source of the bucking voltage is a 1.35 volt mercury battery in series with a voltage divider. The steady-state value of the electrobalance signal is detected by the digital voltmeter. The voltage follower shown in Figure 5-2 is a high-input-impedance operational amplifier, isolating the DVM from the other devices.

\section{CALIBRATION}

Calibration of the balance must be carried out at constant tare weight. If the tare weight is chanyed, then a recalibration of the balance is necessary, because small changes in total weight on the bearing will affect the calibration. Having established a suitable tare weight, calibration of the instrument was accomplished by adding $200 \mathrm{mg}$ of calibrated weights to the measuring arm in increments of $5 \mathrm{mg}$. The individual weights were calibrated to the nearest $10^{-6} \mathrm{gm}$ so that, considering cumulative uncertainties, it was possible to calibrate the balance to the nearest 


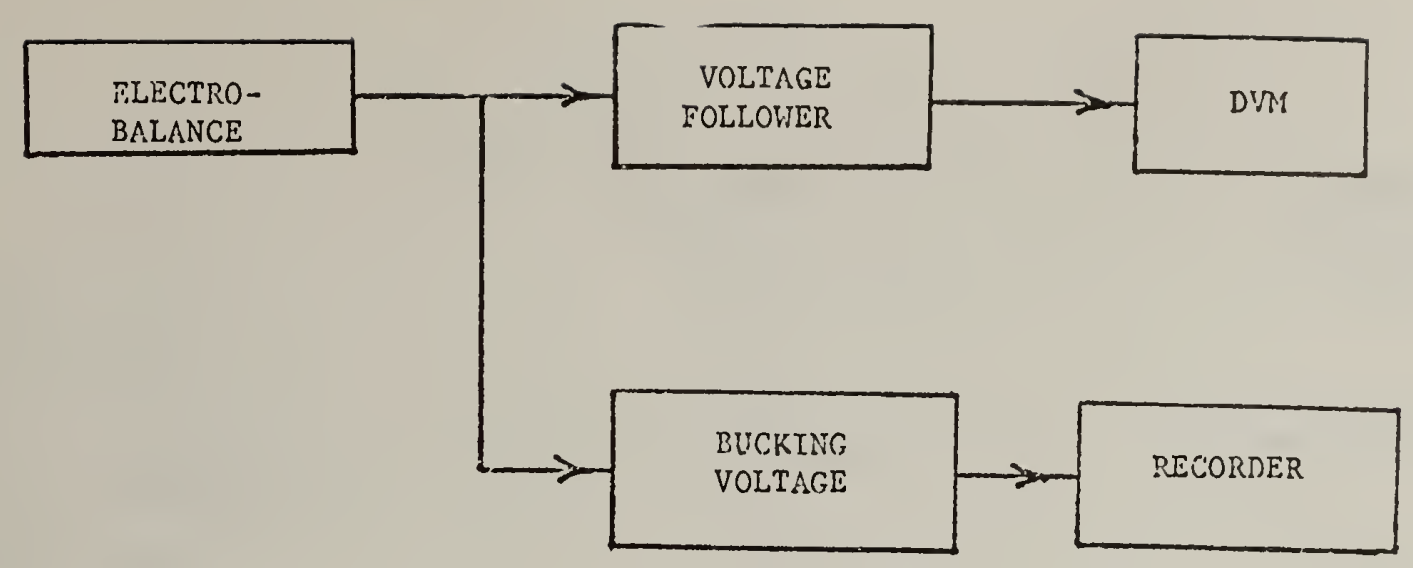

Figure 5-2. Block Diagram of Buoyant-Force-Measuring System

$10^{-5} \mathrm{gm}$. For convenience, the voltage signal from the electrobalance was adjusted so that a $1 \mathrm{mv}$ change in voltage corresponded approximately to a $1 \mathrm{mg}$ change in weight. The precision and accuracy of this measurement have not been determined. The maximum uncertainty in the calculation of specific volume due to weighing errors alone is $\pm 0.0004 \mathrm{~g} / \mathrm{cm}$.

\section{MEASUREMENT OF LIQUID DENSITIES}

In order to calculate specimen density and unfilled void volume using Eqs. 5-3 and 5-5, the densities of the calibration fluid and the dielectric oil must be known. These are measured using a calibrated pycnometer whose temperature is measured to the nearest $0.1^{\circ} \mathrm{C}$. The pycnometer was calibrated by using distilled water to measure its volume with an accuracy of $0.02 \%$.

The pycnometer is filled with sufficient liquid such that air bubbles are not trapped when it is closed. The exterior surface of the pycnometer must be cleaned. Excess liquid on the exterior surface of the pycnometer vessel can be removed by spraying a stream of acetone and by wiping with a piece of lens tissue. Using tongs or gloves, the vessel is then handled and weighed to the nearest $0.1 \mathrm{mg}$.

The results of the density measurements on heptane, decane,alkyl benzene $0 i 1$ and the polybutene oil are listed in Table 5-2. 
Table 5-2

DENSITIES OF LIQUIDS

Specimen

Heptane

Decane

Alkyl Benzene 0il

Polybutene $0 i 1$
Temperature

$22.9^{\circ} \mathrm{C}$

23.2

22.6

23.0

24.7

26.4

22.6

24.2

25.9

26.9
Density

$0.68213 \mathrm{~g} / \mathrm{cm}^{3}$

0.68132

0.72761

0.86679

0.86604

0.86497

0.82922

0.82854

0.82798

0.82745

\section{SPECIMEN PREPARATION}

The specimens used in these experiments were cut from a sheet or strip into pieces $1 \mathrm{~cm}$ square. A hole $2 \mathrm{~mm}$ in diameter was punched in the center of each square, and three or four squares vere then threaded onto the 32-gauge wire loop. This constituted the specimen for that experiment. Specimen weights were in the range $30-60 \mathrm{mg}$.

For the experiments on porous tapes, three materials were chnsen:

- A polypropylene synthetic naper (PPSP), manufact.ured by Matsushita Industrial Equipment Co., Osaka, Japan. See $(\underline{7})$.

- A porous polypropylene (PP) manufactured by Armak Co., Chicago, I11.

- A polyethylene synthetic paper (PE), manufactured by Furukaiva Electric Co., Yokohama, Japan. See (5).

Two dielectric oils were used, some properties of which are shown in Table 5-3:

- An alkyl benzene oil, manufactured by Chevron Chemical Co., Richmond ralifornia, designated Chevron Dielectric 0il 100.

- A polybutene oil, manufactured by Amoco, Wond River, Illinois, designated Cable 01714.

Because of current interest in it, a non-porous laminate of paper-polypropylenepaper (PPP) was measured. This was obtained from Phelps-Dodge Cable and Wire Co., Yonkers, N.Y. The source wad designated in (17) as "Manufacturer B". 
TABLE 5-3

PROPERTIES OF DIELECTRIC OILS

Alkyl Benzene Polybutene

Dielectric Constant $98.89^{\circ} \mathrm{C}$

Dielectric Breakdown $25^{\circ} \mathrm{C}$, by ASTM D877

Power Factor $100^{\circ} \mathrm{C}$

Viscosity $37.8^{\mathrm{O}} \mathrm{C}$
2.1

$>35 \mathrm{kV}$

$>35 \mathrm{kV}$

$0.02 \%$

$0.05 \%$

98 SUS

120 SUS 

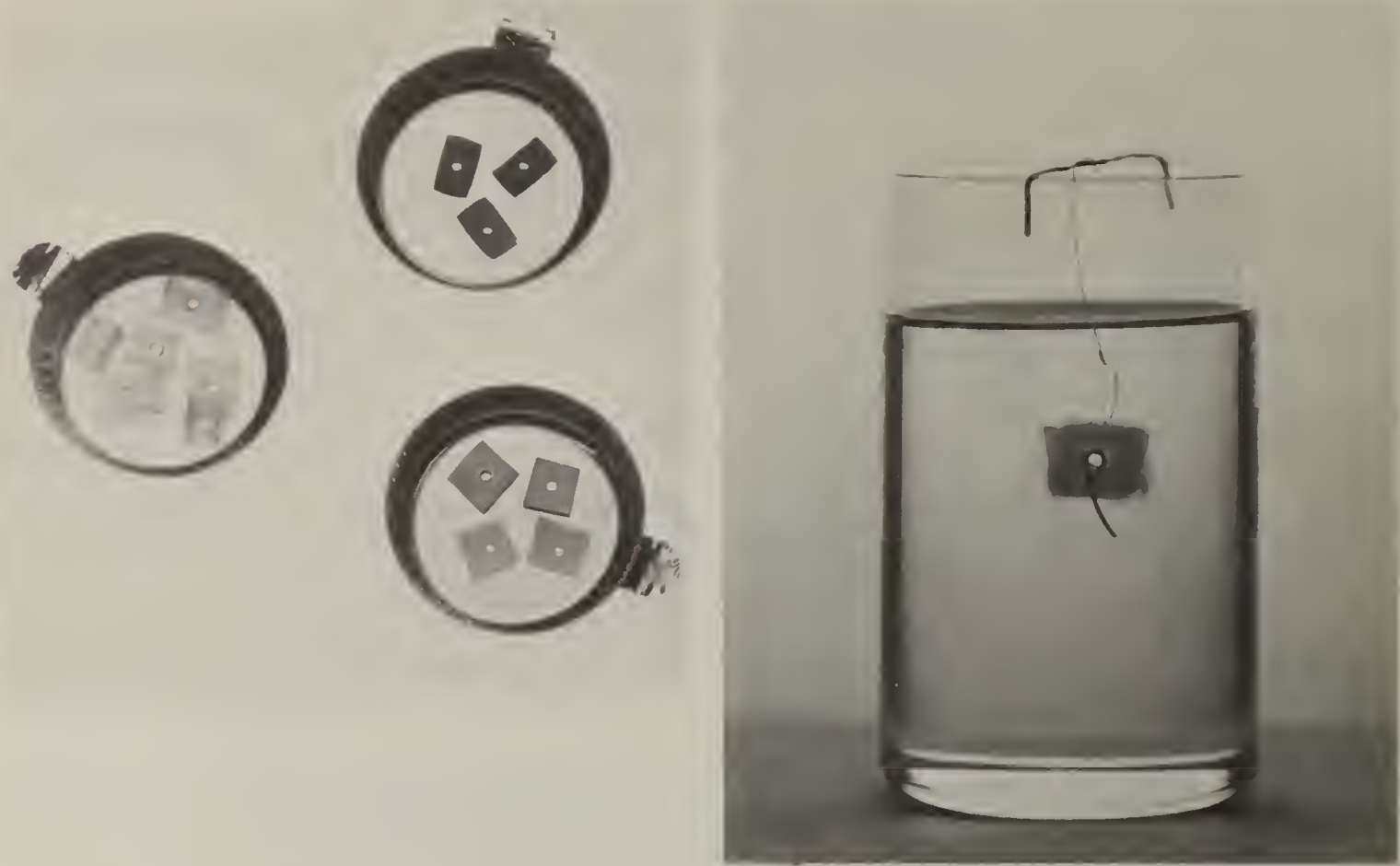

Figure 5-3. Specimens for void-filling test. Clockwise from top: PPP, PP, PE.

Figure 5-4. Specimen of PPP suspended in oi1, as during the buoyancy change measurement, showing the nichrome sinker.

\section{PROCEDURE}

\section{Selection of Calibration Fluids}

The calibration fluid is chosen according to the criteria stated above, i.e. it must effeciently permeate the polymer under test; it must not dissolve the polymer at room temperature; and it must be a volatile liquid which mixes with the dielectric 0i1. Generally, a low-molecular-weight volatile organic liquid is sought for this purpose. A knowledge of permeation coefficients of liquids in various polymer systems can aid in the selection of a calibration fluid. For the polymers investigated in this study, heptane and decane were chosen as calibration fluids hecause it is well known that these liquids permeate polyethylene and polypropylene with ease. 


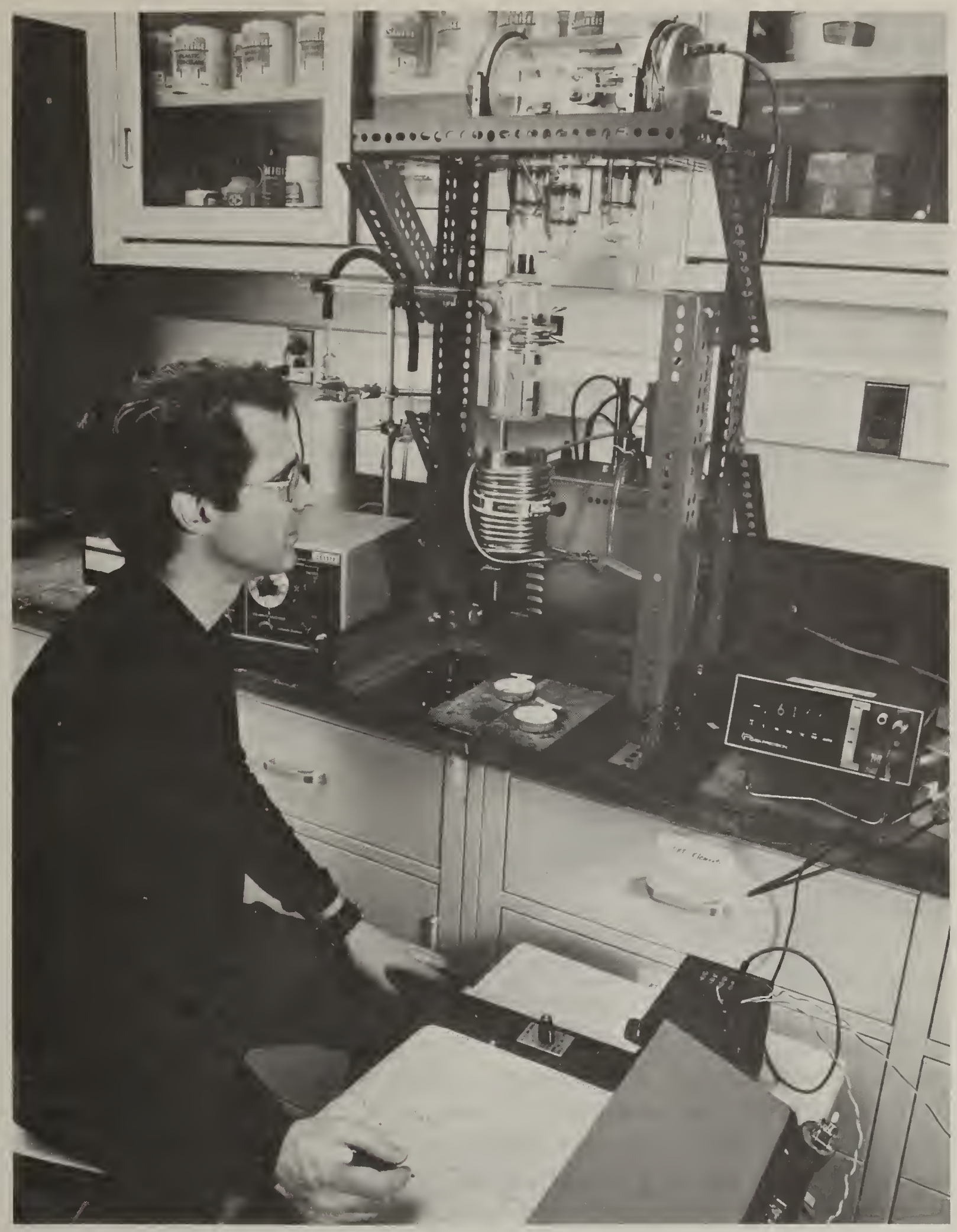

Figure 5-5. Dr. A. J. Bur onerating the void-filling-test apparatus. The rahn Electrobalance is in the horizontal glass cylinder at the top of the photo. The specimen is suspenter in oil in the vertical glass cvlinder. 


\section{Solubility in the Calibration Fluid}

Before we undertake the buoyant force experiments, the solubility of the tape in the calibration fluid is measured. To do this, a specimen weighing approximately $50 \mathrm{mg}$ is weighed to the nearest $0.01 \mathrm{mg}$, using the electrobalance. We then immerse the specimen in approximately $50 \mathrm{~cm}^{3}$ of the fluid. The vessel is retained at room temperature and agitated twice daily over a period of several days. Upon removal from the fluid, the specimen is alternately weighed and vacuum dried until the weight reaches a constant value. If the final weight is within $0.01 \mathrm{mg}$ of the original weight of the specimen, then, within the limits of accuracy of the measurement, the specimen is insoluble in the calibration fluid. This is the ideal case.

In the less-than-ideal case some weight loss occurs. If the loss is less than $0.1 \%$ we consider the fluid to be marginally acceptable, and follow one or the other of two courses of action.

- Short term solubility tests (for periods up to eight hours) can be carried out with new specimens, so that solubility vs. time data can be obtained.

- Alternatively, the original specimen can be retested in order to determine if the weight loss was due to an initial cleaning which does not repeat upon further contact with the fluid. If initial cleaning was the reason for the weight loss, then we gave all subsequent specimens an initial cleaning before using them in the buoyant force experiment.

\section{Measurement of the Specific Volume}

In order to use Eq. 5-3 for the calculation of the specific volume, four balance readings are necessary:

$$
\begin{aligned}
& A=\text { Weight of wire loop and sinker in air, } \\
& B=\text { weight of wire loop and sinker plus specimen in air, } \\
& C=\text { weight of wire loop and sinker in fluid, } \\
& D=\text { weight of wire loop and sinker plus specimen in fluid. }
\end{aligned}
$$

Here, $W_{f}$ of eq. 5-3 is the difference $(D-C)$ and $W_{s l}$ is $(B-A)$. For convenience, we carried out the above measurements in the order $A, C, B, D$. After the measurement of $C$, the wire loop and sinker were thoroughly cleansed either by allowing the fluid to evaporate to by rinsing with a volatile solvent.

Prior to the measurement of $D$, we slowly immersed the specimen into the fluid, being careful to avoid dislodging the wire loop from the balance arm or changing the position of the glass rod. Sudden mechancial jolts to the balance system can disturh the measuring arm and result in a need for a lengthy recalibration procedure. 
Immediately after we immersed the specimen in the fluid and after the vessel was set in place, the bucking voltage was adjusted to cancel out the signal from the electrobalance. A zero reading on the most sensitive scale of the recorder indicated cancellation. As the fluid permeated into the specimen, the change in buoyant force was recorded with time. If this change was larger then the full scale displacement of the recorder, then the bucking voltage was adjusted accordingly. When the buoyant force had reached a constant value which persisted for a period of at least 3 hours, the DVM reading was recorded as the value of $D$.

The same specimen that had been immersed in the calibration fluid is dried and used again with the dielectric oil so that there is no uncertainty regarding the density of the oil-immersed specimen. The procedure as described above for obtaining readings of $A, B$ and $C$ is followed. For $D$, special attention must be given to the oil impregnation process and to the solubility of the specimen in $0 i 1$.

\section{Impregnation Procedure}

$0 i 1$ impregnation is monitored using the chart recorder. When a steady-state or near steady-state value of the buoyant force is reached, a preliminary calculation of the percentage of unfilled void volume is carried out using Eqs. 5-5 and 5-6. If there is a significant amount of unfilled void volume, than vacuum, temperature and pressure (if available) cycling are used in order to achieve maximum degree of void filling. Whatever cycling procedures achieve the optimum will be used for subsequent impregnations.

\section{Solubility in $0 i 1$}

Before a final calculation of $v$ is made, the solubility of the specimen in oil must be determined. To do this the calibration fluid is used as a washing medium after the specimen is removed from the oil. Since the calibration fluid mixes with the dielectric oil, it is possible to remove all of the $0 i 1$ from the pores by repeated washing and drying. Drying can be carried out either by evaporation at ambient room conditions or under vacuum. The weight of the specinen is measured after each wash-dry cycle until a constant weight is reached.

If there is no difference beiween the original and final weight, values of ( $B-A$ ) and $(D-C)$ can be used in Eq. 5-5 without any adjustment. However, if there is a specimen weight loss and it is small, less than $1 \%$, then the value of (B-A) is lowered by the amount of weight loss before using Eq. 5-5. Also, for solubility less than $1 \%$, it can be assumed that the density of $0 i 1$ remains unchanged. 
If the solubility is larger than $1 \%$, then the specimen may be judged unsuitable for continued testing, and, if a calculation of $v_{v}$ is desired it may be necessary to remeasure the density of the oil.

More detail regarding the solubility test is given in Section 6 . 


\section{EXPERIMENTAL RESULTS}

The results of the buoyancy experiments on the three porous tapes and the PPP laminate are given in Tables 5-4 and 5-5 and in Figures 5-6 thru 5-12. The Tables and Figures show that the three specimens of tape cover the extremes from very limited oil penetration (PPSP) to rapid and complete penetration (PP). Void filling of the PE specimen lies between these extremes in that it is not very rapid nor is it complete. Vacuum and temperature cycling were used but were found to have very little effect.

\section{Results - PPSP}

Figure 5-6 shows the change in buoyant force, $\triangle W$, versus time for PPSP in heptane, the calibration fluid. The curve is typical of the calibration data obtained for the PP and PE porous tapes. The weight in air of the PPSP specimen was $43 \mathrm{mg}$. In heptane, the buoyant force gradually changed by $17 \mathrm{mg}$ over a period of $2 \mathrm{hrs}$. This change is interpreted as the effect of diffusion of heptane into the pores and microvoids of the specimen. The steady-state buoyant force was used to calculate the density of PPSP at $23.0^{\circ} \mathrm{C}$ which is $0.9390 \mathrm{~g} / \mathrm{cm}$.

Neither the alkyl benzene oil nor the polybutene oil was able to penetrate the PPSP material to any appreciable degree. Vacuum cycling was used but was found to have very little effect. The purpose was to withdraw trapped gases from the specimen and then open the vessel to atmospheric pressure. A $\Delta W$ versus time curve for PPSP in alkyl benzene oil is not shown because little change with time occurs, i.e., no oil permeation occurs.

The behavior in polybutene oil, which is shown in Figure 5-7, demonstrated evidence of specimen dissolution in the time range from 7 minutes to 80 minutes. On this plot, decreasing $\Delta W$ indicates that the specimen is being dissolved in the oil and increasing $\Delta W$ indicates pore filling. After the PPSP specimen was retrieved from the $0 i 1$, washed in heptane and vacuum dried, a weight loss of $0.07 \mathrm{mg}$ or $0.4 \%$ of the original weight was observed.

Both vacuum and temperature cycling were used for the purpose of improving the oil penetration into the PPSP specimen. The temperature of the immersed specimen was raised to $50^{\circ} \mathrm{C}$ with and without vacuum, and then returned to room temperature. The cycle was repeated using $80^{\circ} \mathrm{C}$ as the maximum temperature. In both cases, the void filling was only slightly improved. We have concluded that temperature and 
Table 5-4.

YOID FILLING AT ROOM TEMPERATURE, ALKYL BENZENE

\begin{tabular}{|c|c|c|c|}
\hline Specimen & $\begin{array}{l}\text { Density in } \\
\text { Heptane or Decane }\end{array}$ & $\begin{array}{l}\text { Density in } \\
\text { Alkyl Benzene } \\
\end{array}$ & $\begin{array}{l}\text { Unfiller Void } \\
\text { Volume-Alkyl Benzene } \\
\end{array}$ \\
\hline & $\mathrm{g} / \mathrm{cm}^{3}$ & $\mathrm{~g} / \mathrm{cm}^{3}$ & $\%$ \\
\hline PPSP & 0.9390 & $\begin{array}{l}0.6474(4 \mathrm{hrs}) \\
0.6738(85 \mathrm{hrs})\end{array}$ & $\begin{array}{l}31.0 \\
28.2\end{array}$ \\
\hline $\begin{array}{l}\text { PPSP after } \\
\text { vacuum }\end{array}$ & & $0.6623(6 \mathrm{hrs})$ & 29.5 \\
\hline PE & 0.9607 & $0.9525(22 \mathrm{hrs})$ & 0.87 \\
\hline $\begin{array}{l}\text { PE after } \\
\text { vacuum }\end{array}$ & & 0.9581 (28hrs) & 0.26 \\
\hline PP & 0.9116 & 0.9114 & 0 \\
\hline PPP & 1.0499 & 1.0451 & see text \\
\hline
\end{tabular}

Table 5-5

VOID FILLING AT ROOM TEMPERATURE, POLYBUTENE

\begin{tabular}{|c|c|c|c|}
\hline Specimen & $\begin{array}{l}\text { Density in } \\
\text { Heptane or Decane }\end{array}$ & $\begin{array}{l}\text { Density in } \\
\text { Polybutene }\end{array}$ & $\begin{array}{c}\text { Unfilled Void } \\
\text { Volume-Polybutene } \\
\end{array}$ \\
\hline & $\mathrm{g} / \mathrm{cm}^{3}$ & $\mathrm{~g} / \mathrm{cm}^{3}$ & $\%$ \\
\hline PPSD & 0.9390 & 0.6232 (4hrs) & 33.5 \\
\hline $\begin{array}{l}\text { PPSP after } \\
\text { vacuum }\end{array}$ & & $0.6542(20 \mathrm{hrs})$ & 30.2 \\
\hline $\begin{array}{l}\text { PPSP after } \\
\text { vacuum, temp. }\end{array}$ & & $0.6853(48 \mathrm{hrs})$ & 27.0 \\
\hline PE & 0.9607 & $\begin{array}{l}0.9267(3 \mathrm{hrs}) \\
0.9562(67 \mathrm{hrs})\end{array}$ & $\begin{array}{l}3.54 \\
0.47\end{array}$ \\
\hline $\begin{array}{l}\text { PE after } \\
\text { vacuum }\end{array}$ & & 0.9573 (90hrs) & 0.35 \\
\hline PP & 0.9116 & 0.9087 & 0.31 \\
\hline
\end{tabular}




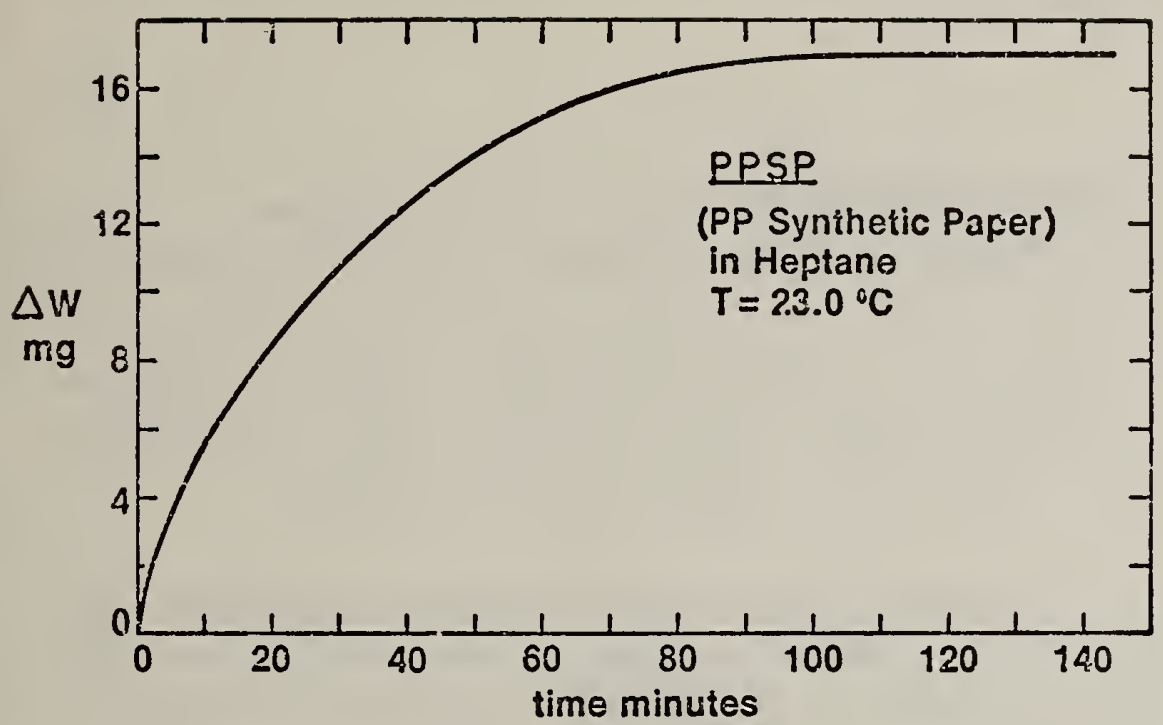

Figure 5-6. The Change in Buoyant Force vs. Time for PPSP in Heptane.

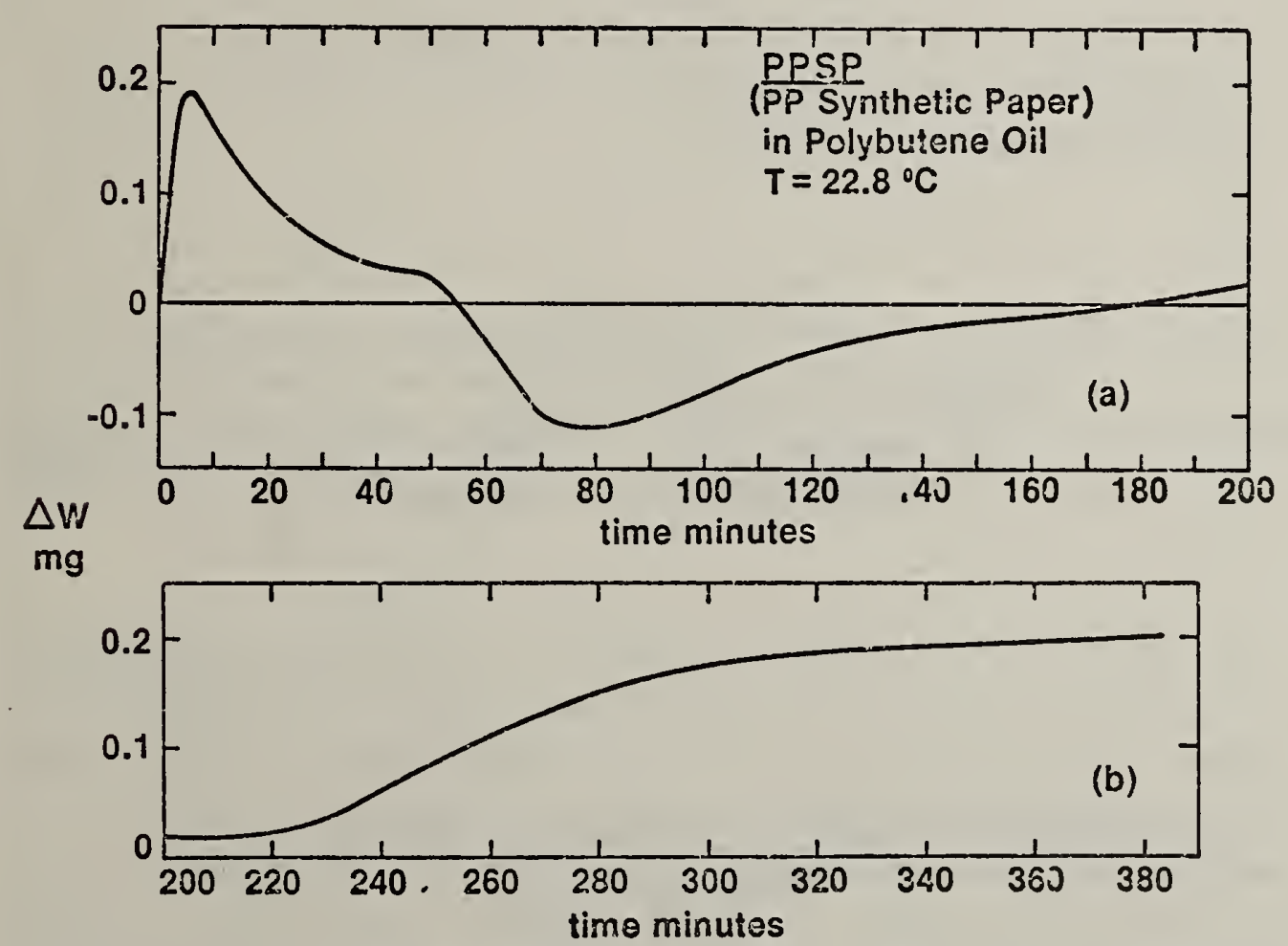

Figure 5-7. The Change in Buoyant Force vs. Time for PPSP in Polybutene 0il; (a) 0-200 minutes; (b) 200-380 minutes. 
vacuum cycling can only be of value for those 0il-polymer combinations for which the oil spreads on the polymer surface. Using either kind of cycling, it is possible to enhance an already good penetration or to bring the permeation to completion, but it is not possible to induce a permeation which is not thermodynamically favorable on mixing the two materials.

\section{Results - PE}

Curves of $\triangle W$ versus time for the PE specimen in the two oils are shown in Figures 5-8 and 5-9. As the data in Tables 5-4 and 5-5 indicate, unfilled void volume is present. Vacuum treatment decreased the volume of unfilled pores, but filling remained incomplete. In Figure 5-9, it appears that pore filling with the polybutene $0 i 1$ proceeds in a stepwise manner. The discontinuity at $t=79$ minutes is interpreted as a sudden release of gas bubbles from the specimen.

Visual inspection of the PE specimens yielded some qualitative information. For example, the porous tapes are opaque in the dry unfilled condition. As the tapes fill with liquid they become transparent. During the filling process, those regions of the tape which have not been penetrated by the oil remain opaque. In the case of the Furukawa polyethylene, gas-filled voids could be observed. These regions expanded when the vacuum was applied and bubbles of gas escaped from those which were near the edge of the specimen. Two voids remained encapsulated and gas was unable to escape from these. Thus, for the PE tapes it could be visually observed that the pore filling was not complete.

\section{Results - PP}

The most efficient oil permeation occurred for the PP specimens. The data of Figures 5-10 and 5-11 show that pore filling for both oils was nearly complete in 20 minutes. Within the limits of accuracy of our measurement, there were no unfilled pores for the alkyl benzene 011 and only $0.31 \%$ for the polybutene $0 i 1$.

\section{Results - PPP}

The $\Delta W$ versus time curve for PPP is shown in Figure 5-12. Initially, 0i1 permeated rapidly into this specimen, but, at $t=5$ minutes, penetration slowed significantly and continued slowly until equilibrium was reached in approximately 24 hours. Good oil permeation was achieved, but, because of variations in density over the area of the original sample sheet, an accurate measure of unfilled void volume can not be obtained from this single measurement. The $0.5 \%$ difference in the numbers of Table 5-4 is probably due to the difference in density of the two samples used in the decane and alkyl benzene. More data, which would permit a statistical analysis of the experiment, is needed for a more precise measurement. 


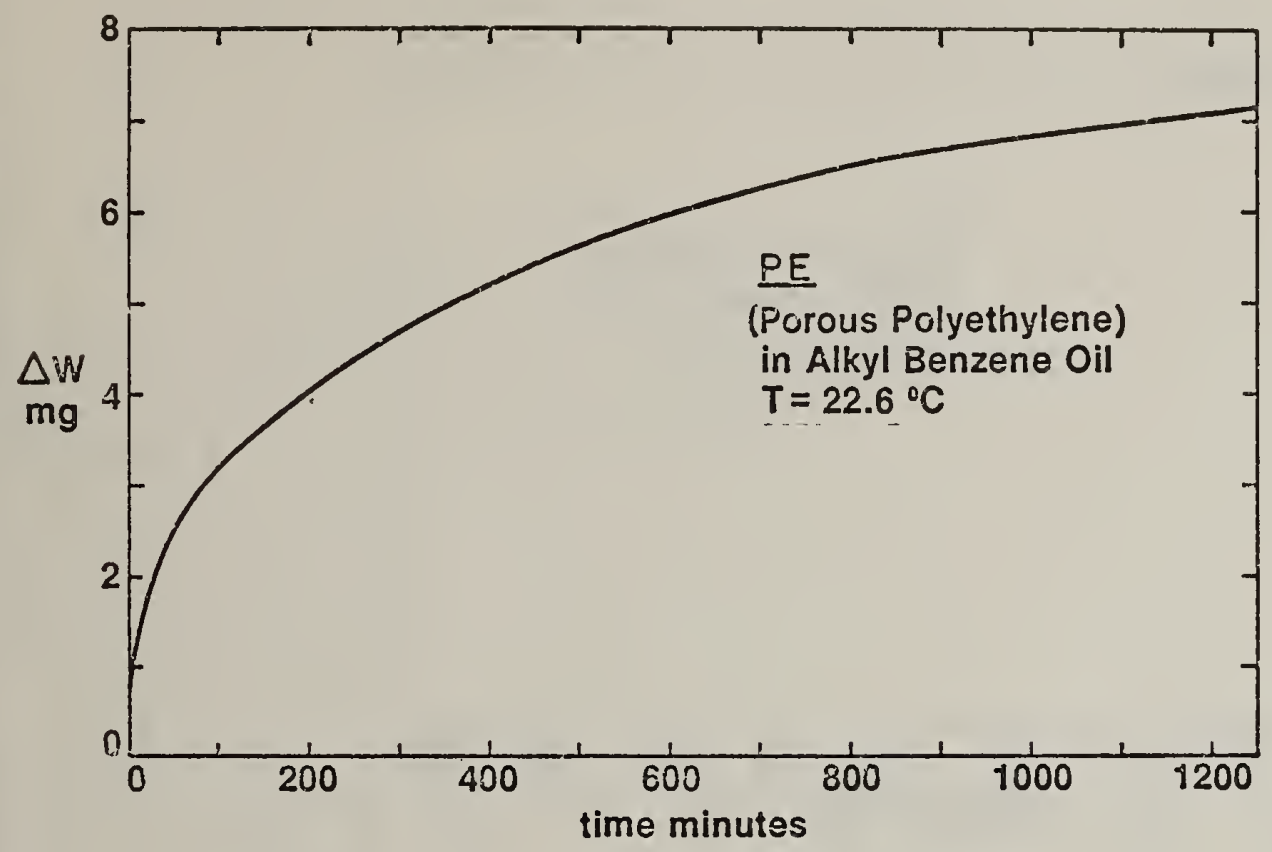

Figure 5-8. The Change in Buoyant Force vs. Time For PE in A.tkyl Benzene 0il.

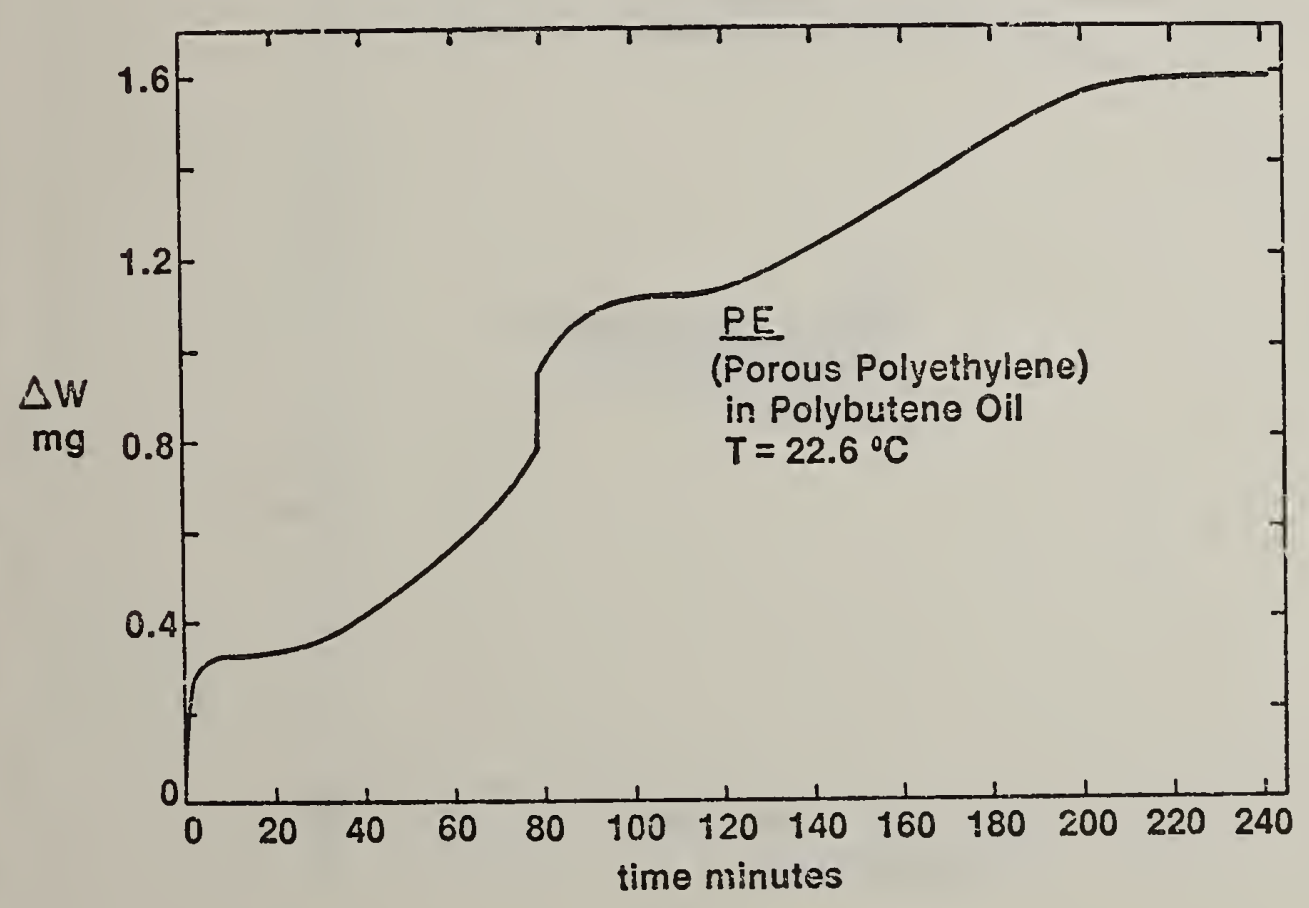

Figure 5-9. The Change in Buoyant Force vs. Time for PE in Polybutene $0 i 1$. 


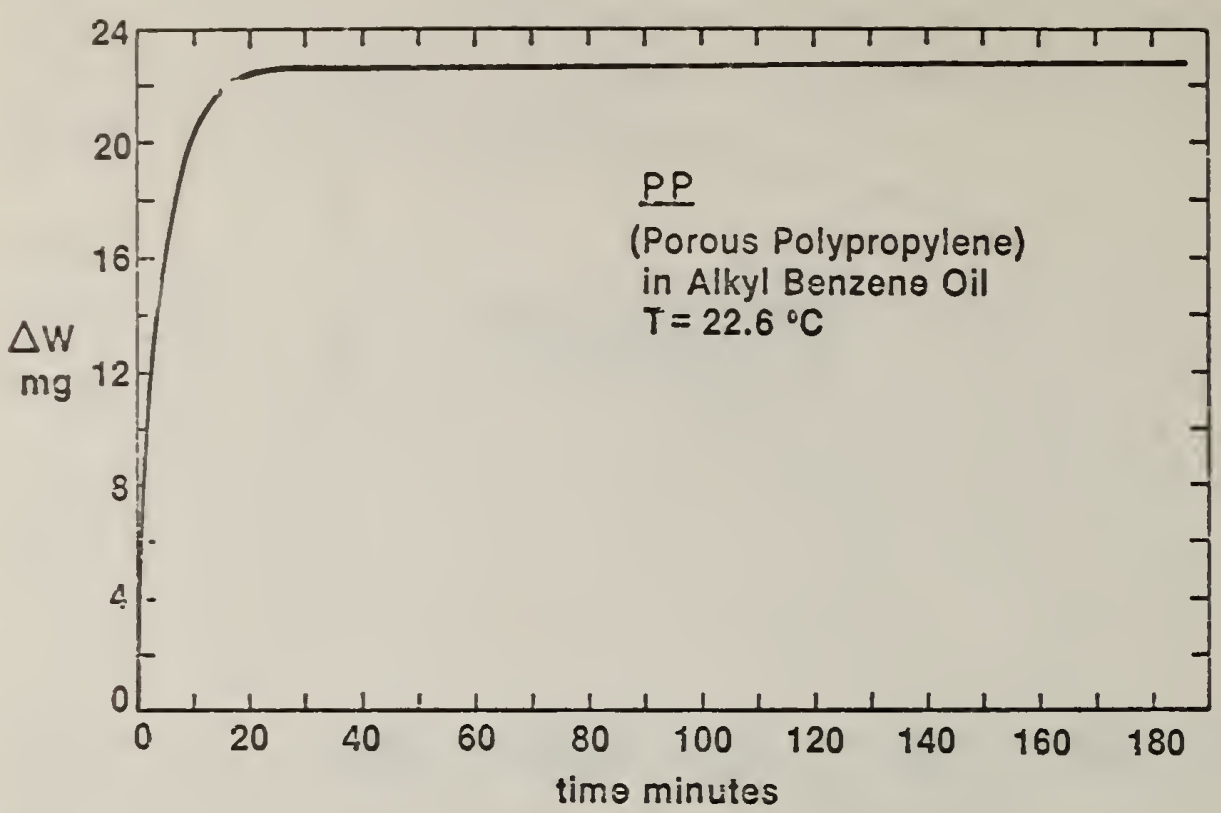

Figure 5-10. The Change in Buoyant Force vs. Time for PP in Alkyl Benzene Dil.

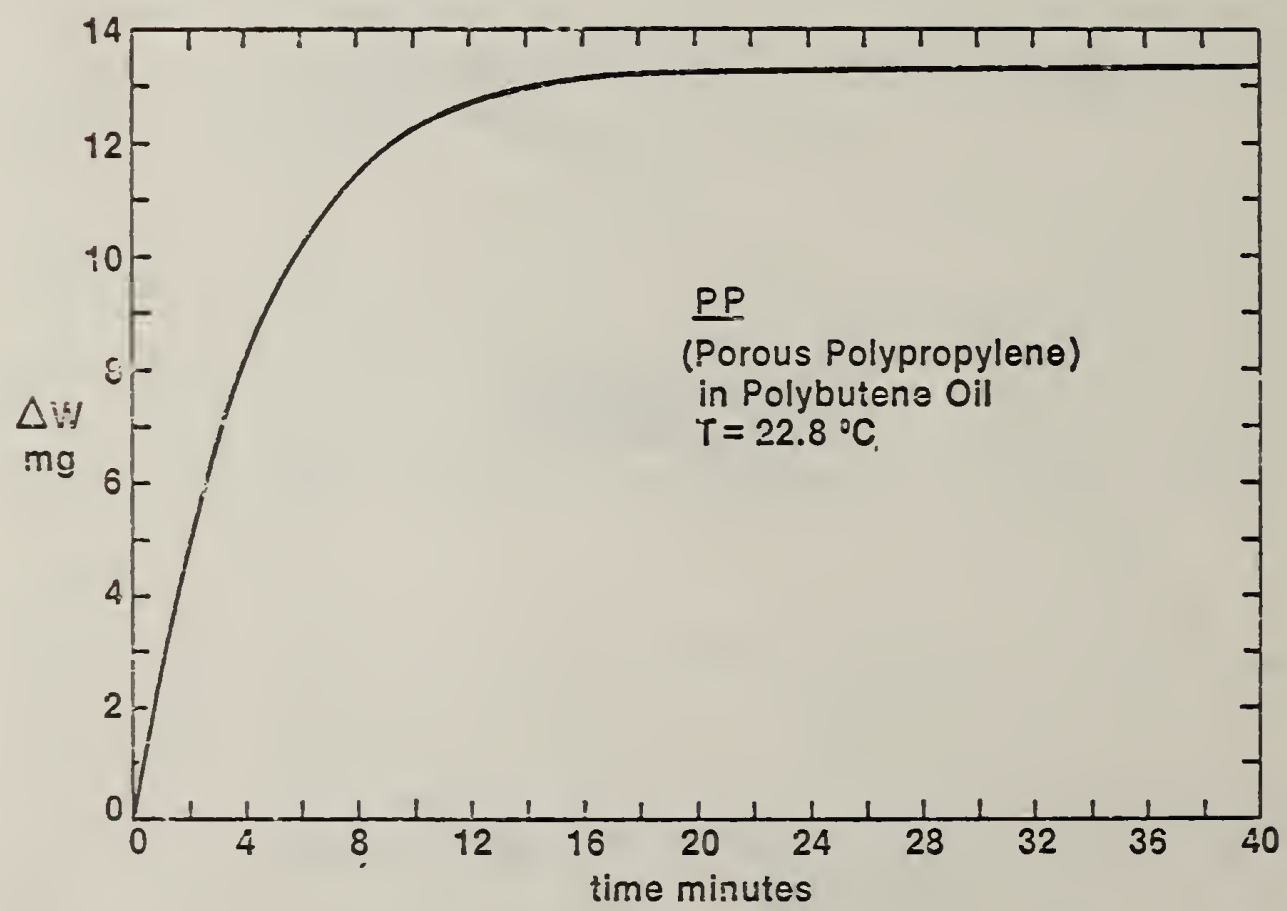

Figure 5-11. The Change in Buoyant Force vs. Time for PP in Polybutene 011. 


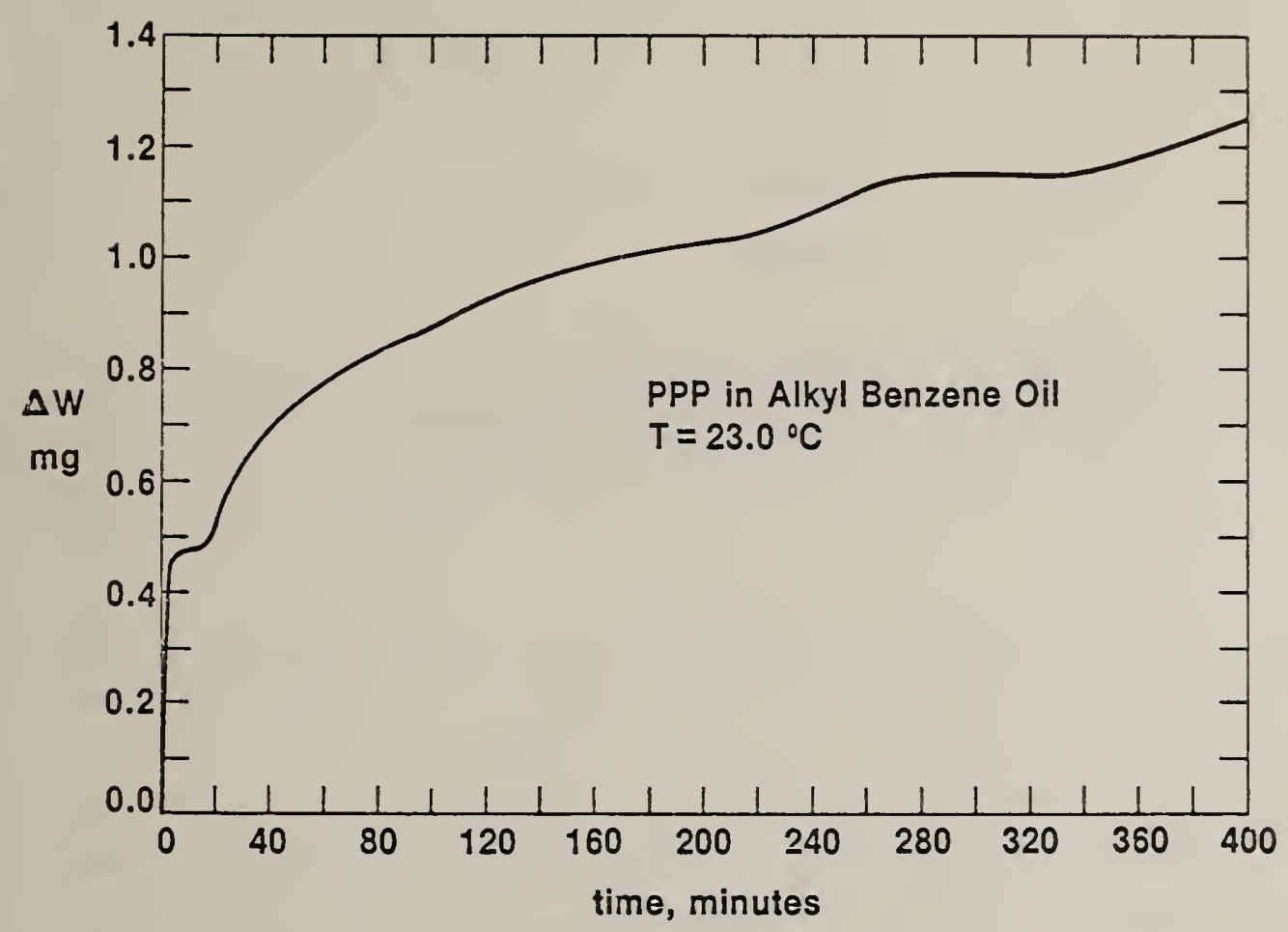

Figure 5-12. The change in Buoyant Force vs. Time for opp in $41 \mathrm{ky} 1$ Renzene $n_{i 1}$ 



\section{SECTION 6}

\section{SOLUBILITY}

In this test solubility of a porous sample in a dielectric oil is measured. Some features of the measurement procedure are described in Section 5 . Use of the calibration fluid to wash the sample after immersion in the oil is an essential step in the procedure.

ASTM D 1239-55 (1971) will be followed for the measurement of solubility with two modifications: a) the specinen must be impregnated with the oil in accordance with the impregnation-time profile which is measured in the degree-of-void-filling test (test 9); b) the specimen is washed in the calibration fluid in order to remove the dielectric oil. The weighing apparatus can be either a precision analytical balance or an electrobalance as described. If an electrobalance is used, specimen size must be tailored so as not to exceed the range of the instrument.

After the original weight of the specimen is obtained, the specimen is immersed in the dielectric oil for the impregnation period. If vacuum cycling was found to be necessary to achieve impregnation in the degree-of-void-filiing test, then the it should be used here also. After impregnation the specimen is placed at one of the testing temperatures: 23,90 or $120^{\circ} \mathrm{C}$. The container should be agitated twice daily for three days. The specimen is then removed from the oil and washed with the calibration fluid at room temperature. Drying is achieved either by evaporation at ambient room conditions or by vacuum drying. The specimen is given as many wash-dry cycles as is necessary for its weight to reach a constant value. When a constant value is obtained, it is compared with the original specimen weight to find a value for the weight lost. The weight lost divided by the original weight multiplied by 100 gives the percent weight loss, or solubility.

Table 6-1 gives the results for the four materials tested. 
TABLE 6-1

Solubility of Tapes at Room Temperature

Weight Loss Weight Loss

Specimen Alkyl Benzene 0il Polybutene

PPSP

0

$0.4 \%$

$P E$

0

0

$\mathrm{PP}$

0

0

PPP

0 


\section{Section 7}

\section{CONCLUSIOHS}

On the basis of previous work on porous polymer tapes and on the basis of a set of reasonable assumptions, it was possible to choose those properties and tests which are of primary importance for application of porous tapes as insulation in underground transmission cables, and to eliminate those properties which are of secondary importance. The essential physical properties of the test program are electrical, mechanical and those properties which are peculiar to porous polymer materials i.e. solubility, melting and softening temperature, degree of void filling, and creep and recovery.

The application of the acceptance criterion for each test requires judgement decisions regarding materials with borderline properties. A trade-off between a desirable property and a borderline property is possible by considering engineering design parameters. For the degree-of-void filling test, the ideal result is that all voids be filled. If, however, it is demonstrated that a small fraction of void volume does not result in deterioration of ac and imoulse breakdown, then the tape can be considered acceptable.

Of the 21 tests in this screening progran it was found that all but two tests were either fully described in published literature or small modifications could be made in a published test without extensive laboratory development.

The feasibility of the buoyant force measurement for obtaining a quantitative measure of the unfilled void volume was demonstrated. This test is used to describe the permeation procedure that is necessary in order to achieve maximum void filling. In those cases where oil permeation is not complete, vacuum and temperature cycling should be employed. The recipe for void filling, which includes the time needed for oil permeation and the necessary cycling procedures, will be used for all tests which require impregnated specimens.

Although we did not use pressures greater than atmospheric to enhance the 0 il impregnation, the conclusions which we reached from our observation of vacuum cycling applied here also. That is, pressure cycling can improve the kinetics of $0 i 1$ 
impregnation for a tape-0il system which spontaneously mixes. It will not, however, cause oil permeation in a tape when it is not thermodynamically favorable. In our judgement, positive pressure is a tool to be used for inpregnating model cables or full size cables after it has been demonstrated by the void-filling test that the oil permeates the material under investigation.

If was found that the calibration fluid served two purposes: (a) Using this fluid the true specimen density was obtained from the buoyant force measurement; and (b) the fluid was used as a washing medium in order to remove all traces of $0 i 1$ from the specimen prior to a solubility determination. Generally for organic polymers the calibration fluid is a low-molecular-weight organic liquid.

The three porous tapes which we used in the development of the solubility and the degree-of-void-filling tests displayed a varied range of void filling. For the PPSP material, we observed that very little oil permeation occured and that the characteristic change in buoyant force with time (indicating oil permeation) did not occur. Although vacuum and temperature cycling were used, we observed only a small change in the unfilled void volume. For PE material, a small fraction of unfilled void volume remained. We were able to use vacuum cycling to improve $0 i 1$ penetration but complete void filling was not achieved for the PE specimens. Only the PP specimen in alkyl benzene oil showed complete oil permeation. We concluded from these experiments with porous tapes that thermodynamically favorable mixing of $0 i 1$ and tape is essential for good permeation.

Although the PPP material does not belong in the category of a porous polymer tape, we measured its void filling characteristic because of current interest in this material. Variations in spatial density of this material were responsible for a higher uncertainty in the measurement of unfilled void volume. A more precise determination requires extended experimentation and statistical analysis. He have concluded that good oil permeation does occur for PPP in alkyl benzene $0 i 1$. 
Section 8

REFEREIICES

1. Polymers Designed for Extra High Voltage Applications. Illinois Institute Of Technology Research Institute Report No. IITRI-48001-57 (1967).

2. 765 kV Pipe Type Cable. Quarterly Reports by Phelps-Dodge Wire and Cable Co., EPRI Contract RP7812, (1972-1978).

3. Development of $500 \mathrm{kV}$ AC Cable Employing Laminar Insulation Other Than Conventional Cellulosic Paper, Final Report by General Cable Corp., EPRI Contract RP7810-1, (1977).

4. Polymer and Polymer/Paper Laminated Tapes for EHV Oil-Filled Cables, by D. R. Edwards, J. Counsel, J. Gibbons and R. Scarisbrick, CIGRE, Paper 15-05, International Conference on Large High Tension Electric Systems, (1972).

5. New Modified Polyethylene Paper Proposed for UHV Cable Insulation, by Z. Iwata, Et.al., IEEE Trans, Power App. Sys., PAS-96, 1573 (1977).

6. Development of Polypropylene Laminated Paper Insulated EHV Cables, by K. Matsuura, H. Kubo, T. Mlyazaki, Underground Transmission and Distribution Conference, 1976.

7. A New Synthetic Paper-MPSP for Insulation, by. A. Tomago, T. Suzuki, A. Iami, and I. Yamauchi, IEEE Trans. Elect. Insu1., EI-12, 301 (1977).

ô. Synthetic Paper for Extra High Voltage Cable, by T. Yamamoto, S. Isshiki, S. Nakayama, IEEE Trans. Power App. Sys. PAS-91, 2415 (1972).

9. Tenax, A Hew Low-Loss High-Temperature Resistant Synthetic Paper for EHV Cables and Other Electrical Equipment, by J. Vermeer et.a1., 1970 Annual Report, Conference on Electrical Insulation and Dielectric Phenomena, p. 56.

10. E. J. :CMahon and J. Punderson, IEEE Trans, Elec. Insul., 3, No. 3 (1973).

11. Electrical Cable With Polymer-0il Insulation, by E. J. McMahon, J. 0. Punderson, W. P. Pitcusky, U. S. Patent No. 3,748,372, (1973).

12. A Program To Evaluate, Develop and Test Poroplastic llaterials as Improved Electrical Insulation For High Power Underground Cables, EPRI Research Project 7842-1, Final Report by Moleculon Research Corp.

13. A Brief Review of the Theory of Paper Tapping of a Single-Core High Voltage Cable, by P. Gazzana-Priagrogia, E. Occhini, and N. Palmieri, Proc. IEE (London) Monograph 3905, 108C, 25 (1960).

14. Some Theoretical Considerations Affecting the Design of Lapoed Plastic Insulation for Super-Conducting Power Transmission Cables, Prepared by Brookhaven National Laboratory, EPRI EL-269, Research Project 7844-1, Appendices A and B, (1976). 
15. Annual Book of ASTIM Stanciards, Published by the American Society for Testing and Materials, Philadelphia, Pa. 19103 (1973).

16. Private Communication, Robert W. Penn, Hational Bureau of Standaras, Washington, D.C. 20234, (1979).

17. E. M. Allam, W. H. Cortelyou and H. C. Doepkin, Low Loss 765 kV Pipe-Type Power Cable. IEEE Trans. Power App. Sys., PAS-97, 2019 (1978).

18. M. G. Hatrella. Experimental Statistics. Handbook 91 Published by U.S. Dept. Commerce, National Bureau of Standards, page 3-24, (1963). 


Below are five index cards that allow for filing according to the four cross-references in addition to the title of the report. A brief abstract describing the major subject area covered in the report is included on each card. For information regarding index card subscriptions to past and future EPRI publications contact the Research Reports Center, P.O. Box 50490, Palo Alto, California 94303. Telephone (415) 965-4081.

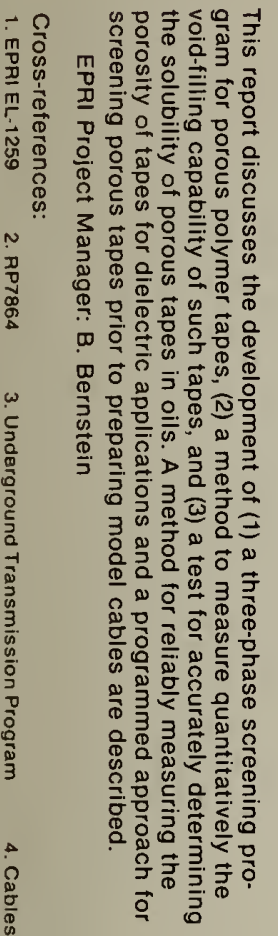

0

\section{7}

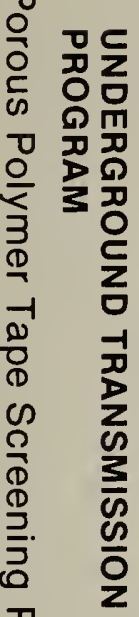
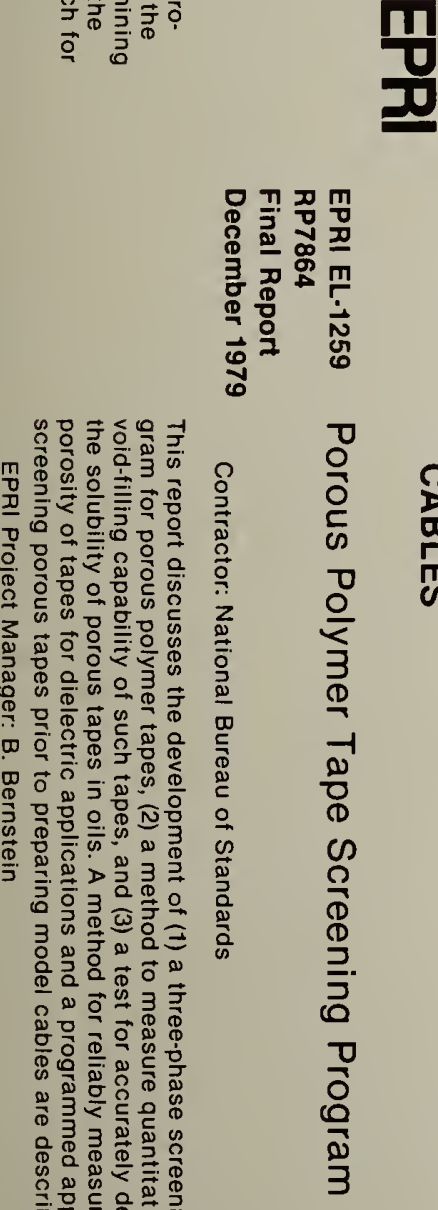

을

\section{EPRI EL-1259 \\ RP7864}

Final Report

December 1979

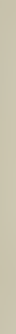

\section{EPRI EL-1259 \\ RP7864 \\ Final Report \\ December 1979}

\section{EPRI EL-1259}

\section{Porous Polymer Tape Screening Program}

Contractor: National Bureau of Standards

This report discusses the development of (1) a three-phase screening program for porous polymer tapes, (2) a method to measure quantitatively the void-filling capability of such tapes, and (3) a test for accurately determining the solubility of porous tapes in oils. A method for reliably measuring the porosity of tapes for dielectric applications and a programmed approach for screening porous tapes prior to preparing model cables are described.

EPRI Project Manager: B. Bernstein

Cross-references:

1. EPRI EL-1259

2. RP7864

3. Underground Transmission Program

4. Cables

ELECTRIC P OWER RESEARCH INSTITUTE Post Office Box 10412, Palo Alto, CA 94303 415-855-2000

\section{RP7864}

\section{EPRI EL-1259 RP7864 Final Report December 1979 \\ Porous Polymer Tape Screening Program \\ Contractor: National Bureau of Standards}

This report discusses the development of (1) a three-phase screening program for porous polymer tapes, (2) a method to measure quantitatively the void-filling capability of such tapes, and (3) a test for accurately determining the solubility of porous tapes in oils. A method for reliably measuring the porosity of tapes for dielectric applications and a programmed approach for screening porous tapes prior to preparing model cables are described.

EPRI Project Manager: B. Bernstein

Cross-references:

$\begin{array}{llll}\text { 1. EPRI EL-1259 } & \text { 2. RP7864 } & \text { 3. Underground Transmission Program } & \text { 4. Cables }\end{array}$ 
